Estudios Constitucionales, Año 16, No 2, 2018, pp. 221-270

ISSN 07180195

Centro de Estudios Constitucionales de Chile Universidad de Talca

"Impacto del Derecho Internacional de los Derechos Humanos en la protección jurisdiccional de grupos en situación de discriminación estructural en Chile" Claudio Nash Rojas - Constanza Núñez Donald

\title{
IMPACTO DEL DERECHO INTERNACIONAL DE LOS DERECHOS HUMANOS EN LA PROTECCIÓN JURISDICCIONAL DE GRUPOS EN SITUACIÓN DE DISCRIMINACIÓN ESTRUCTURAL EN CHILE*
}

\author{
IMPACT OF INTERNATIONAL HUMAN RigHTS LAW \\ ON JURISDICTIONAL PROTECTION OF GROUPS IN SITUATIONS \\ OF STRUCTURAL DISCRIMINATION IN CHILE
}

\author{
Claudio Nash Rojas ${ }^{* *}$ \\ Universidad de Chile, \\ cnash@derecho.uchile.cl \\ ConstanZa NúNÉEZ DONALD ${ }^{* * *}$ \\ Universidad de Chile, \\ cnunez@derecho.uchile.cl
}

\begin{abstract}
RESUMEN: El trabajo que se presenta tiene por objetivo analizar el impacto que ha tenido la aplicación de las normas de Derecho Internacional de Derechos Humanos en la protección jurisdiccional de grupos en situación de discriminación estructural en Chile (migrantes, pueblos indigenas, personas privadas de libertad y mujeres), de manera de determinar si la incorporación de este tipo de normas ha representado una mayor protección para estos grupos. A partir del análisis de la jurisprudencia de las Cortes de Apelaciones y Corte Suprema, se extraen los usos más relevantes del Derecho Internacional de los Derechos Humanos y se determinan los avances y desafios pendientes en la labor jurisdiccional.
\end{abstract}

\footnotetext{
* Trabajo recibido el 14 de noviembre de 2017 y aprobado el 10 de octubre de 2018.

** Doctor en Derecho, Universidad de Chile. Profesor asistente Facultad de Derecho, Universidad de Chile. Director de la Cátedra de Derechos Humanos de la misma Universidad y de la Fundación Diálogo Jurisprudencial Iberoamericano.

*** Licenciada en Ciencias Jurídicas y Sociales de la Universidad de Chile y Máster en Estudios Avanzados en Derechos Humanos Universidad Carlos III de Madrid, Doctoranda en la misma casa de estudios. Académica instructora de la Facultad de Derecho Universidad de Chile.

Este trabajo es el resultado de la etapa final de ejecución del proyecto de investigación Fondecyt No 1150571, titulado "Recepción jurisdiccional sustantiva de la normativa y jurisprudencia internacional en Chile. El proceso de reconfiguración de los derechos fundamentales y su impacto en la protección de grupos discriminados".
} 
ABSTRACT: The paper analyzes the impact that the application of International Human Rights Law has on the jurisdictional protection of groups in situations of structural discrimination in Chile (migrants, indigenous peoples, prisoners and women), to determine if the incorporation of this type of norms has represented a greater protection for these groups. From the analysis of the jurisprudence of the Courts of Appeals and Supreme Court, are extracted the most relevant uses of International Human Rights Law and the advances and pending challenges in the jurisdictional field.

PALABRAS CLAVE: Discriminación estructural; protección jurisdiccional; derecho internacional de los derechos humanos.

KEY WORDS: Structural discrimination; jurisdictional protection; international human rights law.

\section{INTRODUCCIÓN}

El trabajo que se presenta a continuación tiene por objetivo analizar el impacto que ha tenido la aplicación de las normas de Derecho Internacional de Derechos Humanos (en adelante, DIDH) en la protección jurisdiccional de grupos en situación de discriminación estructural en Chile (migrantes, pueblos indígenas, personas privadas de libertad y mujeres), de manera de determinar si la incorporación de este tipo de normas ha representado una mejor protección para estos grupos mediante un uso sustantivo de la normativa internacional ${ }^{1}$.

Entendemos por una mejor protección de derechos, que éstos sean interpretados de la forma más amplia y profunda que permita el sistema normativo complejo (normas de origen nacional e internacional) y que los límites sean los más estrictos con base en una interpretación restringida de la discrecionalidad del Estado para afectar legítimamente derechos humanos. Por otra parte, se entiende como uso sustantivo del DIDH la aplicación de normas del DIDH como criterio determinante u orientador para la resolución, excluyendo del análisis aquellas resoluciones que solo se limitan a enunciar las normas del DIDH como parte de una lista de normas a aplicar. Entendemos por uso sustantivo del DIDH aquella aplicación del DIDH que implica su utilización para: a) concretar principios, b) interpretar derechos consagrados constitucionalmente y legalmente para dotarlos de contenido y alcance, c) integrar derechos para configurar uno nuevo o con un nuevo contenido, d) llenar lagunas, e) inaplicar normas que incumplen las obligaciones internacionales del Estado y, d) servir

\footnotetext{
1 Este trabajo es el resultado de la etapa final de ejecución del proyecto de investigación Fondecyt No 1150571, titulado "Recepción jurisdiccional sustantiva de la normativa y jurisprudencia internacional en Chile. El proceso de reconfiguración de los derechos fundamentales y su impacto en la protección de grupos discriminados".
} 
de parámetro para la determinación de límites a los derechos fundamentales ${ }^{2}$. De esta manera, tanto la mejor protección como el uso sustantivo del DIDH son los dos criterios determinantes para el análisis de la jurisprudencia que se presenta en esta investigación.

Para cumplir con el objetivo propuesto se ha analizado la jurisprudencia de las Cortes de Apelaciones y de la Corte Suprema entre los años 2005-2017, principalmente en acciones de protección y amparo constitucional respecto de los derechos de migrantes, pueblos indígenas, personas privadas de libertad y mujeres. Respecto de cada uno de estos grupos se pondrá de relieve la importancia que ha tenido el DIDH para mejorar la protección de los derechos humanos. Para finalizar, se realizará un balance crítico de la aplicación del DIDH y, prospectivo, con relación a los desafíos que enfrenta a futuro la judicatura para enfrentar la mejor protección de los derechos humanos.

\section{Violaciones ESTRUCTURALES}

Antes de realizar el análisis específico de la protección jurisdiccional en Chile con respecto al impacto del DIDH, es necesario establecer qué entendemos por "violaciones estructurales" a los derechos humanos, como categoría relevante para la selección de los casos referidos a grupos que sufren este tipo de violaciones a sus derechos.

Estas violaciones se caracterizan por que es la organización del Estado (la institucionalidad) la que produce, permite y/o facilita las violaciones de los derechos y libertades fundamentales de ciertos grupos de la población (personas privadas de libertad, pueblos indígenas, migrantes y las mujeres). Además, estas estructuras jurídicas y políticas funcionan sobre la base de ciertos estándares culturales que hacen posible mantener vigentes dichas prácticas violatorias, en particular, la invisibilización de los derechos de los grupos desprotegidos. Por tanto, los esfuerzos para hacer frente a estas violaciones deben apuntar tanto a las condiciones jurídicas y políticas como a las culturales que hacen posible que estas violaciones ocurran ${ }^{3}$.

Las medidas para solucionar la situación de vulnerabilidad extrema descrita compromete la intervención de varias entidades, requiere la adopción de un

2 Sobre esta tipología de usos sustantivos del DIDH en la jurisprudencia nacional, véase los resultados del proyecto de investigación contenidos en: NASH y NúÑEZ (2017).

3 Abramovich (2009) y Aguilo, Bascur y Nash (2014). 
conjunto complejo y coordinado de acciones y exige un nivel de recursos que demanda un esfuerzo presupuestal adicional al Estado de importancia ${ }^{4}$. Para que se produzca este tipo de violaciones de derechos humanos, normalmente, existen omisiones de las autoridades en el cumplimiento de sus funciones constitucionales. Dentro del variado abanico de medidas que se pueden tomar para hacer frente a estas situaciones (políticas públicas, legislativas y judiciales), nos enfocaremos en una concreta, que es la respuesta de los tribunales de justicia (asumiendo, por tanto, que, aunque no sea la única herramienta, es una de las múltiples que deben ser utilizadas para afrontar este tipo de casos). Esta respuesta es particularmente relevante cuando otras herramientas no se utilizan y, en este sentido, poniendo en práctica la labor de garante de los derechos humanos que tienen los tribunales de justicia, éstos pueden colaborar a poner en movimiento estructuras que, por factores culturales, económicos o de otra índole, benefician situaciones de violaciones de derechos humanos.

A continuación, revisaremos la forma en que la jurisprudencia de tribunales superiores ha enfrentado algunos de los casos de violaciones estructurales en Chile.

\section{Protección jurisdiccional en Chile}

\subsection{Migrantes}

La normativa legal vigente en Chile en materia de inmigración fue diseñada en la lógica de incentivar una inmigración selectiva ${ }^{5}$. El D.L. No 1.094 y su respectivo reglamento (Decreto Supremo No 597), regulan el ingreso al país, la permanencia definitiva, el egreso, el reingreso, la expulsión y el control de los extranjeros. En general, estas normas otorgan amplias facultades al Ministerio del Interior para la concesión de visaciones, bajo el concepto jurídico indeterminado de "conveniencia o utilidad para el país" y describen las causales de prohibición de ingreso, que también hacen aplicables como causales de expulsión. Frente a estos déficits que presenta la normativa específica en materia de extranjería,

4 Un desarrollo muy acabado de este elemento lo encontramos en una jurisprudencia de la Corte Constitucional de Colombia, que ha desarrollado la figura del "estado de cosas inconstitucional" donde la respuesta del Estado es clave para configurar esta situación. Véase Corte Constitucional de Colombia, Sentencias T-153/1998 y T-025/2004.

5 Decreto Ley No 1.094 "Establece normas sobre extranjeros en Chile”. Un análisis detallado sobre la normativa legal vigente en materia de migración, en: Centro de Derechos Humanos Universidad de Chile (2016). 
los/as inmigrantes utilizan las normas supletorias (normas administrativas ${ }^{6}$ ). En estos casos la dimensión estructural de las violaciones se ve favorecida por una legislación que aparece como insuficiente para abordar la inmigración con una perspectiva de derechos humanos ${ }^{7}$.

En este contexto, las acciones constitucionales de protección y amparo han desempeñado un rol fundamental para permitir el resguardo de los derechos fundamentales de la población inmigrante frente a decisiones de expulsión o tratos desiguales ${ }^{8}$. Al no existir, además, una normativa específica sobre la materia que tenga un enfoque de derechos humanos, el rol del DIDH ha sido relevante $^{9}$, como veremos, para dotar de contenido al debido proceso, incorporar derechos que no se encuentran en la Carta Fundamental y, en general, por ser un parámetro de evaluación de legalidad de la actuación de la administración.

\section{a) Debido proceso y libertad ambulatoria}

El DIDH ha sido utilizado como parámetro para evaluar la legalidad de los requisitos para disponer medidas de expulsión de extranjeros. En este sentido, en esta temática en particular, el DIDH ha sido utilizado para dotar de contenido al principio del debido proceso y llenar un vacío legal, colaborando en determinar cuáles son los requisitos que debe tener un proceso que culmina con la expulsión del país de un extranjero. Sobre esta cuestión, la normativa internacional ha establecido cuál es el piso mínimo que debe tener un procedimiento para garantizar

6 Por ejemplo, Ley de Bases Generales de la Administración del Estado (Ley No 18.575) y Ley que establece las Bases de los Procedimientos Administrativos (Ley No 19.880).

7 CDH (2016), pp. 101-104.

8 Un estudio sobre la importancia de la acción de amparo para la garantía de los derechos fundamentales de los inmigrantes en Chile, en: Henríquez (2014).

9 Aunque el período de análisis de esta investigación abarca desde el año 2005, lo cierto es que en esta materia sólo desde el año 2013 la incorporación del DIDH por parte de los tribunales superiores de justicia ha ido en aumento. Si en 2011 la aplicación del DIDH era meramente referencial, el año 2017, como veremos, se incorporan como criterios interpretativos incluso Observaciones Generales de Comités de Naciones Unidas. Una de las posibles explicaciones de la progresiva aplicación del DIDH en esta materia a partir del año 2013, lo constituye el hecho de que el Tribunal Constitucional, en una sentencia que constituye un hito en la materia, estableció expresamente que el DIDH forma parte del parámetro o "estándar" bajo el cual debe actuar la autoridad pública en esta materia, véase: Tribunal Constitucional, rol No 2273-2013, 4.07.2013, considerando 50. 
el derecho a ser oído con garantías ${ }^{10}$. Esta circunstancia ha sido reconocida por nuestros tribunales de justicia ${ }^{11}$ y, como parte de la configuración de este "piso mínimo", se ha dotado de contenido al debido proceso mediante la incorporación de las obligaciones específicas que consagra la Convención Internacional sobre la Protección de los Derechos de todos los Trabajadores Migratorios y de sus Familiares ${ }^{12}$ y han establecido que en todo proceso que se pueda expulsar a una persona, esta debe ser oída, ser asistida por un letrado y exponer las razones que le asistan para exponerse a la expulsión ${ }^{13}$. Evidentemente, este mínimo exigible es un avance en relación con las exigencias que establece la actual legislación migratoria, donde no existe un procedimiento específico establecido por ley que cumpla con estas características.

De manera similar al análisis de las órdenes de expulsión, en el caso de las prohibiciones de ingreso, los tribunales de justicia han utilizado el DIDH para determinar los límites que tiene el Estado en el ejercicio de su facultad discrecional para la concesión de visados y en la determinación de prohibiciones de ingreso al país. Este uso corresponde a lo que hemos denominado la función de legitimación de la intervención del Estado ${ }^{14}$, considerando que los derechos fundamentales dejan de ser un mero límite al actuar estatal y se transforman también en un criterio de validez sustantiva de las decisiones. En una decisión central en esta materia ${ }^{15}$, la Corte Suprema señaló que, si bien el Estado posee una facultad discrecional para otorgar visados, debe actuar -en todo caso- conforme a lo dispuesto por la Constitución Política de la República, procurando garantizar los derechos fundamentales ${ }^{16}$.

10 En el ámbito interamericano, véanse, por ejemplo las Opiniones Consultivas de la Corte OC-16/99, OC-18/03 y OC-21/14.

11 Corte de Apelaciones de Copiapó, rol No 290-2015, 20.10.15, considerando 8; rol No 328-2015, 17.11.15, considerando 7; rol No 341-2015, 01.12.15, considerando 8; rol No 202-2016, 10.08.16, considerando 9 y rol No 186-2017, 13.06.17, considerando 7.

12 Corte Suprema, rol No 3990-2017, 16.02.17, considerando 7 y rol No 10916-2014, 30.06.14, considerando 9.

13 Corte de Apelaciones de Copiapó, rol No 290-2015, 20.10.15 y Corte de Apelaciones de Santiago, rol No 2083-2015, 4.12.15.

14 NASH y NúNEZ (2017), pp. 21-23.

15 Hacemos referencia a decisiones adoptadas por tribunales ordinarios, ya que el Tribunal Constitucional, en la sentencia rol No 2273-2012, ya se había referido a esta materia. Un análisis de esta sentencia y sus implicaciones, en: Galdámez (2013) y Didier y Godoy (2014).

16 Corte Suprema, rol No 11521-2014, 12.06.14, considerando 5. 
En este análisis, el DIDH ha cumplido un papel relevante, pues se ha configurado como uno de los parámetros que debe tomarse en consideración a la hora de ejercer la facultad discrecional del Estado y fijar los límites de su actuación, incluyendo la incorporación de las Observaciones Generales del Comité de Naciones Unidas para analizar la proporcionalidad de este tipo de medidas ${ }^{17}$.

\section{b) Derechos de los niños y niñas y protección de la familia}

Otro aspecto, donde la normativa de DIDH ha tenido aplicación en el ámbito migratorio, está relacionado con los derechos de niños y niñas y la protección de la familia. En particular, la protección del derecho de niños y niñas a vivir con su familia (artículo 9.1 Convención sobre Derechos del Niño, en adelante, $\mathrm{CDN}$ ) ha sido uno de los elementos que los tribunales de justicia han tomado en consideración para evaluar la legalidad de las medidas de expulsión del país de personas que mantienen lazos familiares en Chile.

Aunque en la mayoría de los casos la mención al DIDH es solo referencial ${ }^{18}$, es decir, se enuncia la CDN en relación con el artículo $1^{\circ}$ de la Constitución Política (como derechos que deben ser considerados en la decisión de expulsión), en algunos casos ha existido un desarrollo un poco más amplio de las implicaciones de la aplicación de esta normativa. Así, por ejemplo, se han especificado las obligaciones del Estado en cuanto a los derechos del niño/a respecto a la garantía de la protección de la familia ${ }^{19}$ o el DIDH también ha sido utilizado para configurar qué entiende el órgano jurisdiccional por "familia"20.

17 Ídem. En el mismo sentido: Corte de Apelaciones de Iquique, rol No 66-2015, 27.04.15, considerando 5; Corte Suprema, rol No 1059-2015, 20.01.15, considerando 4; Corte de Apelaciones de Iquique, rol No 1052016, 30.08.16, considerando 5; Corte de Apelaciones de Arica, rol No 48-2017, 24.02.17, considerando 5; Corte Suprema, rol № 3990-2017, 16.02.17, considerando 6; Corte Suprema, rol No 10916-2014, 30.06.14, considerando 8; Corte de Apelaciones de Iquique, rol No 56-2015, 31.03.15, considerando 5.

18 Véase, por ejemplo: Corte Suprema, rol No 2309-2015, rol No 3694-2015, rol No 12356-2015, 2.09.15, rol No 9075-2012 y rol No 30361-2017.

19 Corte de Apelaciones de Temuco, rol No 1171-2015, 12.11.15, considerando 5; Corte de Apelaciones de Arica, rol No 196-2017, 4.07.17, considerando 10; Corte de Apelaciones de Temuco, rol No 497-2015, 15.05.15, considerando 5; Corte de Apelaciones de Santiago, rol No 1244-2013, 23.07.13, considerando 10.

20 Corte de Apelaciones de Santiago, rol No 3766-2011, 8.07.11, considerando 6 y rol No 19-2013, 21.01.13, considerando 4 . 
Estas menciones resultan fundamentales porque en el caso de la legislación chilena no existe una norma similar de rango constitucional (con excepción del principio general consagrado en el artículo $1^{\circ}$ ), que permita considerar la importancia de no separar a los niños y niñas de sus padres como parámetro para la realización del juicio de proporcionalidad ${ }^{21}$. Explica la Corte de Apelaciones de Temuco, que este tipo de análisis no supone que se impida adoptar por parte de la autoridad estatal medidas en contra de los extranjeros, sino que, al decretarlas, deben tomarse en consideración elementos tales como el respeto y garantía de los derechos fundamentales de fuente interna e internacional ${ }^{22}$. El DIDH, en este sentido, se transforma en un elemento fundamental en el test de "balanceo" de los intereses y derechos en juego en la evaluación de la constitucionalidad de la decisión.

En un sentido similar, el DIDH también ha sido utilizado para incorporar obligaciones adicionales y complementarias a las que se encuentran en la Carta Fundamental. Por ejemplo, como obligación adicional a las contenidas en la Constitución, se ha incorporado la garantía del derecho a la salud de personas con discapacidad ${ }^{23}$. También, se ha reconocido el derecho a la educación de niños y niñas hijos de inmigrantes a partir de las obligaciones derivadas de la $\mathrm{CDN}$, con relación a las consecuencias que tendría para el derecho de la educación del niño, la expulsión de su padre (quien tenía su cuidado personal), para, por último, establecer que la medida de expulsión debe ser suspendida hasta el término del año escolar del niño ${ }^{24}$.

\section{c) Igualdad ante la ley}

Finalmente, otro tema que ha sido abordado por los tribunales de justicia ha sido el principio de igualdad ante la ley. Sobre esta cuestión, cabe destacar que los tribunales de justicia han reconocido que las personas extranjeras son titulares de los derechos consagrados en el artículo 19 de la Constitución, ya que ésta no hace distinción alguna, de la misma manera en que esto se consagra en tratados

21 Corte de Apelaciones de Antofagasta, rol No 87-2017, 25.04.17, considerando 8.

22 Corte de Apelaciones de Temuco, rol No 1171-2015, 12.11.15, considerando 7.

23 Corte de Apelaciones de Punta Arenas, rol No 8-2017, 28.06.17, considerando 4.

24 Corte de Apelaciones de Santiago, rol No 50535-2015, 20.07.15, considerandos 5 y 9. En un sentido similar, véase: Corte Suprema, rol № 38337-2016, 17.07.16. 
internacionales ${ }^{25}$. Bajo este razonamiento, la Corte Suprema ha declarado que constituye una violación del artículo 19 No 2 de la Constitución impedir a una persona extranjera contraer matrimonio con una persona de nacionalidad chilena, por no tener la persona extranjera cédula nacional de extranjeros (y contar únicamente con su pasaporte) ${ }^{26}$. En este caso, para determinar la existencia de discriminación, se incorporó el derecho a contraer matrimonio como derecho garantizado por la Constitución a través de la remisión al artículo 17 de la Convención Americana sobre Derechos Humanos (en adelante, $\mathrm{CADH}$ ) en relación con el artículo $5^{\circ}$ de la CPR 27.

En este caso, la Corte Suprema realizó un ejercicio de control de convencionalidad ${ }^{28}$ entre el artículo 17 de la CADH y la interpretación de la autoridad administrativa $^{29}$. Así, el DIDH es utilizado como un parámetro para resolver la legitimidad de la legislación interna. En el caso concreto, esto supone concluir que la norma del D.L. de Extranjería se encuentra derogada por ser incompatible con las obligaciones internacionales asumidas por el Estado de Chile.

\subsection{Pueblos indigenas}

El marco normativo constitucional que se refiere a los derechos de los pueblos indígenas en Chile está constituido por la Constitución Política, el Convenio 169 de la OIT sobre Pueblos Indígenas y Tribales en Países Independientes, la Declaración de Naciones Unidas sobre Pueblos Indígenas (2007) y la Declaración Americana sobre Derechos de Pueblos Indígenas (2016). El principal instrumento internacional aplicado por la jurisprudencia nacional en relación a los derechos de los pueblos indígenas ha sido el Convenio 169 de la

25 Corte de Apelaciones de Santiago, rol No 51704-2015, 20.08.15, considerando 5.

26 En el caso la persona en cuestión estaba en situación administrativa irregular, por encontrarse vigente un decreto de expulsión en su contra.

27 Corte Suprema, rol No 35237-2016, 30.08.17, considerando 10. Con anterioridad habían existido pronunciamientos similares, pero que solo hacían una referencia genérica a los tratados internacionales sobre derechos humanos, véase por ejemplo: Corte de Apelaciones de Santiago, rol No 53381-2015, 7.08.15, considerando 5 .

28 Ferrer Mac-Gregor contenido en la obra de HenríqueZ y Morales (2017) y también NúNez (2016) y NASH (2013).

29 En el mismo sentido: Corte de Apelaciones de Santiago, rol No 13932-2017, 4.05.17, considerando 6 y Corte Suprema, rol No 32081-2014, 30.08.16, considerando 5. 
OIT $^{30}$. Desde su entrada en vigencia, los pueblos indígenas han utilizado este instrumento como herramienta jurídica para exigir sus derechos frente a los tribunales de justicia ${ }^{31}$.

En Chile, la jurisprudencia ha ido avanzando desde la simple enunciación del Convenio como una más de las normas jurídicas a considerar, hacia la aplicación sustantiva de sus estándares. Como ha señalado la Corte de Apelaciones de Temuco, "el Convenio 169 sin duda enriqueció la Ley Indígena No 19.253, ya que perfecciona y llena de contenido los preceptos de dicha ley" 32 .

Como veremos, en el caso de los pueblos indígenas las violaciones estructurales se facilitan no solo por la falta de incorporación de la perspectiva cultural en la legislación, sino también por parámetros interpretativos restrictivos a la hora de incorporar la perspectiva cultural en el análisis judicial.

\section{a) Eximentes de responsabilidady modalidades diferenciadas de cumplimiento de la pena}

En ámbito penal, el Convenio 169 de la OIT otorga diversas herramientas para garantizar en condiciones de igualdad, el pleno goce y ejercicio de los derechos por parte de los pueblos indígenas, a través de la consideración de la situación particular en la que se encuentran (pobreza y exclusión) y de su identidad cultural.

A este respecto, uno de los casos más relevantes, en que se comenzó a incorporar al razonamiento jurídico el Convenio 169 de la OIT, es el caso Blas. Los hechos que lo originaron ocurrieron el año 2007, cuando Gabriela Blas Blas (aimara) denunció ante Carabineros la pérdida de su hijo mientras ella pastoreaba en la zona altiplánica. Circunstancias posteriores develaron la muerte del niño, lo que llevó a Gabriela Blas a ser juzgada en sede penal. Lo interesante de este caso es que la defensa introdujo la vigencia del Convenio 169 de la OIT para que se considerara que los hechos se dieron en el contexto de la práctica de una costumbre ancestral de pastorear junto a los hijos. Pese a que la utilización

\footnotetext{
30 Diversos estudios se han realizado acerca del impacto jurisprudencial del Convenio 169 de la OIT en Chile, principalmente en relación en materia de consulta previa, véase: MeZa-LopeHANdía (2016) y Fuenzalida (2015). Sin embargo, como veremos a continuación, esta no ha sido la única materia donde se ha dado uso al Convenio.

31 Courtis (2009), p. 60.

32 Corte de Apelaciones de Temuco, rol No 3385-2014, 21.11.14, considerando 7.
} 
del Convenio no redundó en un juicio a favor de la imputada (porque a juicio del tribunal no se logró probar la costumbre), resulta relevante destacar que el tribunal, al momento de analizar la normativa nacional respecto a la costumbre indígena, consideró el Convenio como un elemento relevante en el análisis ${ }^{33}$.

Existen casos similares, en que los recurrentes han invocado las normas del Convenio 169 para justificar la aplicación de atenuantes o penas diferenciadas en consideración a la costumbre. En dichas oportunidades, los tribunales han estimado que si bien por aplicación del Convenio 169 de la OIT debe considerarse la costumbre en un juicio penal, no se ha aplicado en la práctica por estimarse que la costumbre no estaba probada ${ }^{34}$, no resultaba determinante para el caso concreto $^{35}$, o bien la costumbre no justificaba la acción imputada (no operaba como causal de justificación) ${ }^{36}$. Un ejemplo en que sí resultó aplicable la consideración de la costumbre lo encontramos en el caso Alto Bío Bío, donde la Corte Suprema aceptó la aplicación de una aminorante de la conducta, al considerar las características sociales y culturales del pueblo pehuenche. En efecto, en este caso se consideró que la violencia perpetrada por los agresores al desalojar por medio de la fuerza a un grupo de personas que ocupaba un territorio se explica por la importancia del amparo de la tierra y de la identidad cultural, lo que revela que para el pueblo pehuenche las infracciones que vulneran la propiedad son de una gravedad relevante ${ }^{37}$. Esto llevó a la Corte Suprema a concluir que era procedente la aplicación de una aminorante de la sanción.

Asimismo, el Convenio también se ha utilizado para alterar la modalidad de cumplimiento de las sanciones penales. En efecto, con base en el artículo 10 No 1 del Convenio, la Corte de Apelaciones de Temuco (dando aplicación directa a este artículo y añadiendo obligaciones complementarias al Estado) ha señalado que en consideración a este artículo era necesario tomar en cuenta la situación socioeconómica del imputado, lo que la llevó a concluir que era pernicioso para el imputado la reclusión en un centro penitenciario, determinando

\footnotetext{
33 TOP Arica. RIT No 221-2009, 11.10.10, considerando 14. El caso de Gabriela Blas llegó hasta el sistema interamericano de derechos humanos, donde se llegó a una solución amistosa ante la CIDH y se reconoció la responsabilidad del Estado de Chile en la violación de derechos humanos de la señora Blas, véase petición P-687-11.

34 Corte de Apelaciones de Temuco, rol No 99-2009, 25.02.09, considerando 5.

35 Corte Suprema, rol No 6041-2012, 26.09.12, considerando 8.

36 Corte Suprema, rol No 28842-2015, 20.01.16.

37 Ibídem, considerando 5.
} 
que debía cumplir la pena en su domicilio ${ }^{38}$. Sin embargo, aplicando el mismo artículo, la Corte Suprema ha indicado que la consideración de factores culturales no es dotada de un contenido preciso por parte de los recurrentes "puesto que se ha omitido explicar aquel ámbito de la cosmovisión de la etnia mapuche y de las creencias del amparado que podría verse afectado de continuar con su encarcelamiento"39.

En este sentido, los problemas que se identifican con la aplicación del Convenio 169 para justificar una aplicación diferenciada de la ley penal (ya sea como eximente o para justificar un cumplimiento alternativo de la pena), no dicen relación con el valor jurídico que se otorga al Convenio ni con la necesidad de su aplicación, sino más bien con la prueba de la costumbre indígena en juicio ${ }^{40}$, las dificultades se relacionan con que existe un desconocimiento del juzgador respecto a los elementos que configuran la costumbre.

\section{b) Aplicación de acuerdos reparatorios}

Junto con la aplicación del Convenio 169 para justificar eximentes de responsabilidad penal y modalidades diferenciadas de cumplimiento de la pena, también destaca su utilización para argumentar la adopción de acuerdos reparatorios en causas sobre violencia intrafamiliar entre víctimas e imputados mapuche. Pese a estar prohibido este tipo de acuerdos en la legislación sobre violencia intrafamiliar, las cortes aceptaron su aplicación sobre la base de los artículos $9^{\circ}$ y 10 del Convenio, señalando que es un hecho probado de que el pueblo mapuche resuelve sus conflictos a través de la conciliación ${ }^{41}$. En este sentido, el Convenio ha sido utilizado para introducir formas propias de resolución de conflictos del

38 Corte de Apelaciones de Temuco, rol No 711-2011, 17.08.11, considerando 1. En el mismo sentido: Corte de Apelaciones de Antofagasta, rol No 149-2017, 2.06.17 y rol No 231-2017, 10.08.17. De manera contraria a esta tendencia, la Corte de Apelaciones de Temuco, por las modificaciones sufridas en la Ley No 18.216 considera que no es posible aplicar medidas alternativas en virtud del Convenio № 169 en casos donde es obligatoria la ejecución de la pena efectiva, Corte de Apelaciones de Temuco, rol No 11562016, 15.11.16, considerando 3.

39 Corte Suprema, rol No 1274-2015, 27.01.15, considerando 7.

40 Bertini y Yáñez (2013).

41 Esta solución fue aceptada por algunos tribunales de justicia, véase: Corte de Apelaciones de Temuco, rol No 581-2012, 2.08.12; rol No 499-2012, 17.07.12 y rol No 955-2011, 27.10.11. Sobre este debate, véase: Palma y Sandrini (2014); Centro de Derechos Humanos Universidad de Chile (2013) y Carmona (2015). 
pueblo mapuche en el ámbito penal. No obstante, este acercamiento de la jurisprudencia a la problemática no ha estado exento de críticas ya que el mismo Convenio establece el límite a la aplicación de la costumbre indígena, cual es, los derechos humanos internacionalmente reconocidos y la legislación interna ${ }^{42}$.

Otro caso que puso en evidencia estas tensiones (referidas a la conciliación de estándares internacionales y sus límites internos) fue la sentencia rol No 692016 de la Corte de Apelaciones de Valdivia, sobre la omisión de aplicación de estándares internacionales sobre derechos de los niños y niñas (referidos a la explotación laboral), priorizando la aplicación del Convenio 169 de la OIT ${ }^{43}$.

De esta forma, el Convenio 169 de la OIT es utilizado para justificar la aplicación de la costumbre indígena, pero también para restringir su uso en atención a los límites propios que el Convenio establece.

\section{c) Protección de la integridad cultural}

Uno de los aspectos centrales del Convenio 169, es la protección de la integridad cultural de los pueblos indígenas. Sus artículos $2^{\circ}, 4^{\circ}$ y 13 consagran, en general, la obligación de los Estados de desarrollar políticas que promuevan el respeto y protección de sus costumbres, tradiciones e instituciones. Sobre la base de esta normativa, los tribunales nacionales han interpretado el artículo 19 No 6 de la Constitución Política (libertad de conciencia y ejercicio libre de los cultos) desde una perspectiva de derechos colectivos, referente al derecho de los pueblos indígenas a mantener su integridad cultural.

En el caso Kintuantü, la Corte de Apelaciones de Valdivia, señaló que la tala ilegal iniciada sobre árboles milenarios, que constituyen el cordón de protección y parte esencial del Ngen Mapu Quintuante, impedía el normal desarrollo de las manifestaciones religiosas y espirituales del pueblo mapuche. Lo relevante de este caso es que, junto con interpretar el derecho a la libertad de culto desde una perspectiva colectiva, la Corte de Apelaciones de Valdivia reconoce que el Convenio 169 de la OIT contiene el estándar mínimo para el ejercicio de los derechos fundamentales de los pueblos indígenas ${ }^{44}$. Similares consideraciones se realizaron por la Corte de Apelaciones de Arica en el caso proyecto Minero

42 Corte de Apelaciones de Temuco, rol No 220-2013, 3.05.13.

43 Corte de Apelaciones de Valdivia, rol No 69-2016, 25.06.16.

44 Corte de Apelaciones de Valdivia, rol No 501-2011, 4.05.12, considerandos 12, 13, 14 y 15. 
Manganeso Los Pumas. En este caso, un proyecto minero buscaba emplazarse en un lugar relacionado con la divinidad andina. La Corte, a partir de una revisión de la cosmovisión andina y su relación con el agua, y con base en las obligaciones que establece el Convenio 169 (artículos 4º $5^{\circ}$ y 13), estableció que la probable afectación -por mínima que sea- de la vertiente de la quebrada de Tarapacá, al erigirse como un lugar conectado con la divinidad andina en la cosmovisión aimara, amenaza la garantía constitucional del artículo 19 No 6 de la Constitución Política ${ }^{45}$.

El artículo 19 No 16 de la Constitución también ha sido aplicado en conjunto con el Convenio 169 de la OIT a propósito del derecho a la educación. En el caso de un establecimiento educacional que había sido multado por no contar con un docente con preparación católica en un colegio mapuche, la Corte de Apelaciones de Temuco - aplicando el Convenio 169 de la OIT y la Convención de Derechos del Niño- entendió que no procedía aplicar en este caso la multa, ya que debía interpretarse la obligación interna a la luz de los nuevos paradigmas consagrados en los tratados internacionales que vinculan la identidad cultural con su identidad religiosa ${ }^{46}$. En este caso hay una manifestación concreta de un ejercicio de control de convencionalidad que implica que en este caso no sea aplicado un Decreto interno, para dar cumplimiento con las obligaciones internacionales del Estado.

\section{d) Acción constitucional de amparo y protección a la libertad personal y seguridad individual}

Con ocasión de la situación de violencia contra las comunidades mapuche por parte de las policías en la Araucanía, la Defensoría Penal Pública y el Instituto Nacional de Derechos Humanos han interpuesto acciones de amparo constitucional a favor de personas pertenecientes a comunidades mapuche (en su mayoría niños y niñas), en contra de Carabineros de Chile, denunciando actos que constituyen amenazas a la libertad personal y seguridad individual. En este contexto, han invocado las normas del Convenio 169 de la OIT, para complementar la fundamentación respecto a la proscripción del uso ilegítimo de la fuerza y la necesidad de utilizar la fuerza de manera proporcional. Dichas

45 Corte de Apelaciones de Arica, rol No 182-2013, 25.11.13, considerandos 37, 38 y 39. Véase también: Corte Suprema, rol No 3010-2013, 26.09.13, considerandos 8 a 11.

46 Corte de Apelaciones Temuco, rol No 4512-2015, 11.11.15, considerandos 5 y 6. 
argumentaciones han sido recogidas por la jurisprudencia, y si bien en algunas oportunidades se han desestimado los amparos interpuestos, sí se han indicado que los estándares bajo los cuales debe desarrollarse la actuación policial son los del Convenio 169 de la OIT ${ }^{47}$.

De esta forma, las Cortes fijan los estándares de actuación policial no solo con base en el artículo 19 No 7 de la Constitución Política (derecho a libertad y seguridad personales) sino también considerando las obligaciones que impone el Convenio. En este sentido, el Convenio se transforma en un estándar de conducta que debe seguir la autoridad policial y el instrumento internacional es el criterio orientador de la actuación pública.

\section{e) Tierras y propiedad indigena}

Uno de los aspectos centrales del Convenio, y que ha influido en avanzar hacia una nueva concepción del derecho de propiedad en la jurisprudencia de la Corte IDH y en los demás países de la región ${ }^{48}$, es el concepto de territorios que introduce. El artículo 13 No 2 aclara que "la utilización del término tierras en los artículos 15 y 16 deberá incluir el concepto territorios, lo que cubre la totalidad del hábitat de las regiones que los pueblos interesados ocupan o utilizan de alguna otra manera”.

Este concepto amplio de territorio también ha tenido recepción en la jurisprudencia nacional. En efecto, esta noción ha sido utilizada para interpretar el artículo 64 de la Ley Indígena y darle una aplicación conforme a las obligaciones internacionales. El caso Comunidad Chusmiza-Usmagama es un ejemplo de este ejercicio ya que la Corte Suprema interpretó la Ley Indígena a la luz de los artículos 15 No 1 y 13 No 2 del Convenio 169 y reconoció el derecho de la comunidad aimara sobre las aguas que han utilizado ancestralmente ${ }^{49}$. Este modelo de razonamiento se replicó en el caso Pepiukelen, donde la Corte de Apelaciones de Puerto Montt indicó que hoy, por aplicación del artículo 13 No 2

47 Corte de Apelaciones de Temuco, rol No 1136-2011, 21.12.11, considerando 5 y rol No 449-2012, 5.07.12, considerando 8, entre otras. Un estudio sobre la utilización de la acción de amparo respecto de comunidades indígenas, en: DPP (2012).

48 Courtis (2009), pp. 61-62.

49 Corte Suprema, rol No 2840-2008, 25.11.08, considerando 7. 
del Convenio 169 de la OIT, el concepto de tierras indígenas es más amplio y considera lo que el tribunal llama el "hábitat de una comunidad indígena" 50 .

Como explicamos y ha reconocido la jurisprudencia nacional, el Convenio 169 permite una interpretación de la normativa nacional que incorpora el concepto territorio, ampliando los alcances del derecho de propiedad tradicional, lo que posibilita la protección de la comunidad en su conjunto y el ejercicio de sus derechos con relación a sus costumbres en referencia a la tierra.

\section{f) Consulta previa}

Otro de los aspectos fundamentales, donde se ha invocado y aplicado el Convenio 169, dice relación con la obligación de realizar una consulta previa e informada, respecto de medidas que sean susceptibles de afectar directamente a los pueblos indígenas. Sobre esta materia hay dos tópicos que han sido tratados en la jurisprudencia nacional: la suficiencia e insuficiencia de los instrumentos de participación interna a la luz de las exigencias del convenio y los principios que deben ser aplicados en este procedimiento.

La primera aproximación jurisprudencial que se manifestó en un comienzo en los tribunales nacionales, fue estimar que -en consideración al carácter flexible de la consulta- era suficiente con las normas de participación ciudadana que contemplaba la normativa ambiental para considerar que se había cumplido con el trámite de consulta previa ${ }^{51}$. Esta tendencia jurisprudencial se revirtió en los casos Comunidad Mapuche Huilliche Pepiukelen ${ }^{52}$, Consejo de Pueblos Atacameños ${ }^{53}$ y Comunidad Indígena Antu Lafquén de Huentetique ${ }^{54}$ y la Corte Suprema comenzó a desarrollar una tendencia jurisprudencial dirigida a reconocer las particularidades de la consulta previa y a caracterizarla de acuerdo a los estándares mínimos que se deben cumplir para su realización a partir del Convenio

\footnotetext{
50 Corte de Apelaciones de Puerto Montt, rol No 36-2010, 27.07.10, considerando 10. El destacado es nuestro. En el mismo sentido: Corte de Apelaciones de Temuco, rol No 445-2015, 19.08.15, considerando 3.

51 Corte Suprema, rol No 4078-2010, 14.10.10, considerandos 5, 6 y 7. En el mismo sentido: Corte de Apelaciones de Arica, rol No 9-2011, 4.03.11, considerando 14 y rol No 359-2011, 2.11.11, considerando 14; Corte de Apelaciones de Santiago, rol No 1794-2010, 31.01.11, considerando 10 y; Corte de Apelaciones de Puerto Montt, rol No 239-2011, 11.10.11, considerandos 8 y 9.

52 Corte de Apelaciones de Puerto Montt, rol No 36-2010, 27.07.10.

53 Corte Suprema, rol No 258-2011, 13.07.11.

54 Corte Suprema, rol No 10090-2011, 22.03.12.
} 
169 de la OIT. En el caso Consejo de Pueblos Atacameños, la Corte Suprema no solo indica las características especiales que debe tener la consulta, resaltando la insuficiencia de los instrumentos de participación que establece la normativa nacional, sino que también establece un criterio interpretativo relevante y que será acogido con posterioridad por la jurisprudencia, y es que señala que todas las medidas que puedan afectar la realidad de los pueblos indígenas deben ser llevadas a cabo en consideración de sus particularidades culturales, teniendo como referencia para ello el Convenio 169 de la OIT55.

El segundo caso en que la Corte Suprema recoge estas argumentaciones, se origina a propósito de una acción de protección interpuesta por la Comunidad Indigena Antu Lafquén de Huentetique en contra de la resolución de la Comisión Regional del Medio Ambiente de la Región de Los Lagos, que calificó favorablemente el proyecto "Parque Eólico Chiloé". La Corte, además de reiterar la importancia de realizar la consulta previa con las características reseñadas en el fallo anterior ${ }^{56}$, señala que la decisión es ilegal pues lesiona la garantía de igualdad ante la ley, porque al no aplicarse la consulta que el Convenio dispone, niega trato de iguales a dichas comunidades indígenas ${ }^{57}$.

Además, la jurisprudencia ha desarrollado aspectos particulares respecto al contenido y características del proceso de consulta. Por ejemplo, se aprecia de manera paulatina que los tribunales de justicia comienzan a incorporar los estándares internacionales (jurisprudencia de la Corte IDH y recomendaciones de organismos internacionales), para interpretar las obligaciones que establece el Convenio 169. En el caso Comunidad Huallenmapu, la Corte de Apelaciones de Temuco para interpretar los artículos $6^{\circ}$ y $7^{\circ}$ del Convenio, tomó en consideración los estándares sobre principios internacionales aplicables a la consulta elaborados por el relator James Anaya ${ }^{58}$.

Las líneas jurisprudenciales descritas constituyen un avance para el reconocimiento de los derechos de los pueblos indígenas y para la implementación del Convenio 169 de la OIT en Chile, ya que se reconoce la obligatoriedad de la

\footnotetext{
55 Corte Suprema, rol No 258-2011, 13.07.11, considerandos 5 y 8. El destacado es nuestro. En el mismo sentido: Corte Suprema, rol No 11040-2011, 30.03.12, considerando 9; rol No 10090-2011, 22.03.12, considerando 8; rol No 65349-2016, 30.01.17, considerando 5, y Corte de Apelaciones de Valdivia, rol No 2149-2014, 3.01.14, considerando 8.

56 Corte Suprema, rol No 10090-2011, 22.03.12, considerando 8.

57 Ibídem, considerando 9.

58 Corte de Apelaciones de Temuco, rol No 1920-2012, 15.12.12, considerando 10.
} 
consulta y la importancia que tiene esta para las posibilidades de las comunidades indígenas de influir en las decisiones administrativas que puedan alterar su entorno y condiciones de vida. Al reconocer la identidad cultural y la importancia de ésta para el diseño de proyectos y políticas públicas es posible una efectiva protección y goce de los derechos cuando los titulares son pueblos indígenas acorde a estándares internacionales ${ }^{59}$.

Debemos aclarar, en todo caso, que esta es una tendencia favorable de la Corte Suprema respecto a considerar las especificidades de la consulta contenida en el Convenio 169 de la OIT como parámetro de legalidad de las Resoluciones de Calificación Ambiental (RCA), pero que aún no está consolidada ${ }^{60}$.

Una última aclaración necesaria. Hasta el año 2014, la sede donde se discutía la conformidad de los procesos de consulta a la luz de las obligaciones internacionales del Estado eran las Cortes de Apelaciones y la Corte Suprema mediante acciones constitucionales de protección. Sin embargo, desde el año 2014, la Corte Suprema ha sostenido que los Tribunales Ambientales son la sede jurisdiccional competente para discutir la legalidad de una resolución de calificación ambiental ${ }^{61}$.

\subsection{Personas privadas de libertad}

En el artículo 76, la Constitución reconoce la garantía de la jurisdicción para la persona condenada. A nivel legal, en el Código Procesal Penal se encuentran consagradas una serie de disposiciones destinadas a reconocer los derechos fundamentales de las personas imputadas y condenadas, además de recoger

59 Corte IDH. Caso Pueblo Indigena Kichwa de Sarayaku vs. Ecuador, párr. 159.

60 A favor de considerar la especificidad de la consulta como proceso participativo que garantiza la igualdad en virtud de las disposiciones del Convenio 169, véase: Corte Suprema, rol No 65349-2016, 30.01.17. En contra: Corte Suprema, rol No 1515-2014, 22.04.14.

61 Véase, por ejemplo: Corte Suprema, rol No 2892-2014, 29.04.14, considerando 7; rol No 1097-2013; rol No 11299-2014; rol No 35244-2016, rol No 44037-2016; Corte de Apelaciones de Temuco, rol No 6822016, 26.05.16. Por ello, gran parte de la jurisprudencia analizada es anterior a esta fecha, sin perjuicio de aquellas sentencias que se pronuncian en casación sobre resoluciones dictadas por tribunales ambientales. Esta aproximación debe ser asumida con cautela, ya que, si bien es cierto que los Tribunales Ambientales han asumido la competencia para calificar la legalidad de las RCA, no debemos olvidar que la consulta es un derecho humano y, como tal, siempre debe tener la posibilidad de ser garantizado a través de una acción tutelar que sea efectiva. Un buen análisis de este proceso en la Memoria de Grado elaborada en el marco de este proyecto Fondecyt, Contreras (2018). 
estándares internacionales sobre procedimientos penales ${ }^{62}$. Por su parte, a nivel reglamentario, el Reglamento de Establecimientos Penitenciarios (REP) regula las materias referentes a la administración interna del régimen penitenciario al interior de los penales del país y también consagra en forma general ciertos principios orientados para la protección de las personas privadas de libertad ${ }^{63}$.

En la práctica, esta regulación, básicamente reglamentaria, ha permitido que medidas que afecten los derechos fundamentales de los reclusos y reclusas queden bajo un régimen de suma discrecionalidad administrativa y sin un control externo adecuado. Por ello, la acción de amparo constitucional ha sido una de las herramientas jurídicas para hacer frente a violaciones estructurales de derechos humanos, como son las condiciones en que las personas privadas de libertad cumplen sus condenas, a través de un entendimiento amplio de lo que significa la seguridad personal ${ }^{64}$.

A continuación, algunos ejemplos de las diferentes materias sobre las que se ha pronunciado la jurisprudencia respecto de los derechos de las personas privadas de libertad.

\section{a) Seguridad de las personas privadas de libertad}

Atendida la situación de dependencia que tienen las personas privadas de libertad con el Estado, este asume una posición de garante de sus derechos. En un caso concreto, mediante una acción de amparo, se discutió ante la Corte de Antofagasta ${ }^{65}$ si un interno que resulta lesionado a consecuencia de hechos que no pueden ser atribuidos a un acto de autolesión, pueden ser atribuidos a la responsabilidad de la institución a cargo del recinto, esto es, Gendarmería de

62 Horvitz y López (2002), pp. 53-100. En el artículo 7o del Código Procesal Penal, se reconocen las oportunidades para hacer valer derechos y garantías, al señalar que las "facultades, derechos y garantías que la Constitución Política de la República, este Código y otras leyes reconocen al imputado (...) podrán hacerse valer hasta la completa ejecución de la sentencia”.

63 Decreto No 518. Reglamento de Establecimientos Penitenciarios. Santiago, 22 de mayo de 1998. Última modificación 20 de diciembre de 2011. Se modificó este Reglamento Penitenciario con el objeto de adaptar materias referentes a la administración penitenciaria a los estándares del derecho internacional de los derechos humanos. Al respecto ver, Horvitz y López (2002), p. 586 y Kendall (2010), p. 33.

64 Sobre la "ampliación" del habeas corpus en este tipo de casos, véase: Henríquez (2013). Un buen ejemplo de las medidas que los tribunales paulatinamente van tomando para hacerse cargo de las cuestiones relacionadas con las condiciones carcelarias, véase: Corte de Apelaciones de Valdivia, rol No 140-2017, 8.08.17.

65 Corte de Apelaciones de Antofagasta, rol No 37-2014, 28.07.14. 
Chile. La Corte de Antofagasta razona en el sentido de que las personas privadas de libertad tienen restringida su libertad personal, pero siguen siendo titulares de sus derechos humanos, tal como lo ha sostenido la Corte Interamericana a quien cita ${ }^{66}$. Sobre esa base la sentencia razona en el sentido de determinar quién es el responsable de la seguridad del amparado y concluye que Gendarmería es responsable al no haber tomado los resguardos para evitar las lesiones que se constataron en el caso ${ }^{67}$. En un caso similar, en 2016, la Corte de Apelaciones de Chillán ${ }^{68}$, resolviendo una acción de amparo constitucional, estableció que las obligaciones de cuidado que establece la normativa interna de Gendarmería debe vincularse con el deber del Estado de ser "garante de la seguridad individual" conforme al Derecho Internacional ${ }^{69}$.

En estos casos, es la normativa internacional, y particularmente la jurisprudencia de la Corte Interamericana, la que permite dar concreción al derecho a la seguridad personal de que son titulares las personas privadas de libertad y establece, como consecuencia, la responsabilidad de la institución a cargo de la persona privada de libertad. Este derecho no está expresamente consagrado, pero puede desprenderse de la reglamentación de Gendarmería y para dicho proceso de concreción es utilizado el estándar internacional.

\section{b) Aplicación de sanciones y beneficios penitenciarios}

Uno de los problemas más graves en materia de acceso a la justicia de personas privadas de libertad se produce cuando éstas son objeto de medidas disciplinarias al interior de los recintos penitenciarios ${ }^{70}$. En una sentencia de la Corte de Apelaciones de Iquique ${ }^{71}$ se discutió, precisamente, el tema de la aplicación de sanciones a internos en el marco de los hechos ocurridos con ocasión de un movimiento telúrico ocurrido en la ciudad que provocó pánico al interior de la cárcel de Iquique y trajo, como consecuencia, la aplicación de sanciones. En

66 Ibídem, considerando 6.

67 Ibídem, considerando 7.

68 Corte de Apelaciones de Chillán, rol No 339-2016, 5.04.16.

69 Ibídem, considerando 9. A continuación, la sentencia cita los arts. 7 y 10.1 del PIDCP y art. 5.2 de la $\mathrm{CADH}$.

70 Sobre el derecho de acceso a la justicia de personas privadas de libertad, véase: AguiLÓ, MiLos y NaSH (2013).

71 Corte de Apelaciones de Iquique, rol No 113-2014, 14.11.14. 
este caso, la Corte de Iquique señaló que las personas privadas de libertad tienen derecho a un debido proceso y para fundar dicha aseveración utiliza la jurisprudencia de la Corte Interamericana en materia de acceso a la justicia ${ }^{72}$ y las Reglas Mínimas de Naciones Unidas para el Tratamiento de Reclusos de $1955^{73}$. Sobre esta base, determina que el derecho que tienen los internos a un debido proceso para la imposición de sanciones no se había dado en el caso concreto, por lo que acogió la acción constitucional de amparo.

Otro caso relativo a la aplicación de sanciones es uno relativo a un adolescente privado de libertad al que se le mantuvo engrillado, por varios días, de pies y manos en una celda de castigo sin luz y separada de las áreas centrales del recinto. La Corte de Apelaciones de Copiapó ${ }^{74}$ estableció como criterio general que "[...] independientemente de la infracción al régimen disciplinario en que pudo haber incurrido el adolescente, lo cierto es que la sanción derivada de ello debe ajustarse plenamente al respeto de sus derechos, y en tal sentido no sólo debe resultar proporcional a la falta, sino que su cumplimiento no puede importar de forma alguna un desmedro de su integridad física o psíquica, ni menos aun una infracción a las leyes o reglamentos"75. Para determinar el alcance de la obligación del Estado en relación con los derechos humanos de adolescentes privados de libertad, la Corte de Apelaciones cita a la Corte Interamericana de Derechos Humanos, en su resolución dictada en el Asunto de los Niños y Adolescentes Privados de Libertad en el Complexo do Tatuapé da FEBEM respecto de Brasil (Resolución de 30 de noviembre de 2005) ${ }^{76}$.

Como vemos, en esta materia, por el déficit normativo en cuanto a la regulación de los castigos, la Corte utiliza sustantivamente los estándares internacionales para dar concreción a un derecho que no se encuentra explícitamente desarrollado en la normativa reglamentaria sobre recintos penitenciarios. De esta forma, el DIDH se utiliza para llenar un vacío normativo y dar concreción a un principio general (presunción de inocencia como parte del debido proceso), estableciendo un parámetro de actuación de la autoridad estatal.

\footnotetext{
72 Ibídem, considerandos 4 y 6.

73 Ibídem, considerando 6.

74 Corte de Apelaciones de Copiapó, rol No 263-2016, 13.10.16.

75 Ibídem, considerando 3.

76 Ibídem, considerando 4.
} 


\section{c) Igualdad ante la ley}

En materia de discriminación basada en identidad de género, que afecta el derecho a la igualdad ante la ley, la Corte de Apelaciones de Iquique ${ }^{77}$ dictó una sentencia en que utilizó el DIDH para configurar los alcances de la discriminación en un recinto penitenciario en contra de una interna transgénero. En el caso se recurrió de amparo constitucional frente a actos discriminatorios en razón de identidad sexual y malos tratos desarrollados en el complejo penitenciario de Alto Hospicio (en el contexto de un procedimiento de seguridad gendarmes obligaron a desnudarse a una interna frente al resto de la población y la revisaron por personal masculino siendo objeto de burlas, además, en el allanamiento a su dormitorio destruyeron su ropa interior (femenina). El hecho de que la denunciante era una mujer transgénero había sido comunicado oficialmente a las autoridades del recinto penitenciario. Lo primero que hace la sentencia es aclarar los términos. En el oficio de Gendarmería dando cuenta de la situación ocurrida se había usado la expresión 'orientación sexual', por lo que la Corte estimó pertinente aclarar que el caso se refería a un asunto sobre identidad de género. Para aclarar los términos, la sentencia cita al Comité de la Convención para la Eliminación de Toda Forma de Discriminación contra la Mujer (Naciones Unidas) y los principios de Yogyakarta ${ }^{78}$. A continuación, la sentencia revisa las normas relevantes aplicables al caso, dentro de la cuales cita el PIDCP y la $\mathrm{CADH}^{79}$. Asimismo, cita a la Corte Interamericana ${ }^{80}$, en relación con las obligaciones del Estado en materia de discriminación por identidad de género ${ }^{81}$. La Corte resolvió que el trato recibido por la recurrente sí configuraba una violación de la Constitución, la CADH y el PIDCP.

En este caso, el uso del DIDH sirve no solo para dar contenido y alcance a la prohibición de discriminación, sino que también permite vincular dicha discriminación con una violación a la integridad personal. Ni el alcance de la prohibición de discriminación a la identidad de género ni su vínculo con la integridad personal sería posible sin esta referencia a los estándares normativos (tratados, resoluciones internacionales) y jurisprudenciales referidos.

77 Corte de Apelaciones de Iquique, rol No 859-2016, 9.12.16.

78 Ibídem, considerando 2.

79 Ibídem, considerando 3.

80 Ibídem, considerando 4.

81 En concreto, la Corte cita el caso Duque vs. Colombia. 
Otro tema donde se ha discutido la infracción a la igualdad ante la ley ha sido el derecho a sufragio de personas privadas de libertad. En un caso ante la Corte de Apelaciones de Temuco, se reclamó por parte del INDH que las personas privadas de libertad, que no se encuentran excluidas de la calidad de ciudadano ni suspendido su derecho a sufragio, ven limitada su posibilidad de participación, lo cual constituiría un acto violatorio de sus derechos constitucionales (acción de protección por violación del art. 19 No 2 y 19 No 12). Dicha acción fue rechazada por el Tribunal de alzada, por considerar que no había un acto ilegal ni arbitrario ${ }^{82}$.

En el mismo tema, la Corte Suprema resolvió que constituía una violación constitucional no adoptar por parte de la autoridad administrativa todas las medidas necesarias para garantizar el derecho de sufragio a los internos en recintos penales que no habían sido objeto de una sanción que restringiera sus derechos políticos ${ }^{83}$. Para argumentar, la Corte Suprema tiene en consideración que Gendarmería de Chile tiene el deber de "velar de manera activa por que se respete la condición de ciudadano de cualquier persona privada de libertad bajo su custodia, teniendo en consideración al efecto no sólo la normativa interna sino también las disposiciones internacionales incorporadas a nuestro ordenamiento legal" 84 . A continuación, la Corte revisa los distintos instrumentos internacionales de DD.HH. que consagran derechos políticos para concluir que "el derecho a sufragio como un derecho ciudadano, que debe ser garantizado en su ejercicio por el Estado y puede estar sujeto a eventuales restricciones que no pueden extenderse más allá de las señaladas en el respectivo instrumento, quedando excluida la privación de libertad como medida cautelar, como ocurre en el presente caso, o cuando la condena no lleva aparejada la pérdida del derecho a sufragio" 85 . Para luego citar a la Corte Europea e Interamericana en materia de restricción de derechos políticos de personas privadas de libertad ${ }^{86}$. Finalmente, la Suprema concluye que el actuar de la administración es ilegal ${ }^{87}$.

82 Corte de Apelaciones de Temuco, rol No 6143-2016, 13.12.16.

83 Corte Suprema, rol No 4764-2017, 9.05.17.

84 Ibídem, considerando 6.

85 Ibídem, considerando 7.

86 Ibídem, considerando 9.

87 Ibídem, considerando 10 . 
En estos casos el uso del DIDH es relevante para fijar el alcance de una restricción de derechos, como lo es la restricción al derecho a sufragio de personas privadas de libertad. Aquí la limitación de derechos, conforme al principio pro persona, debe ser interpretada restrictivamente y, para fijar el alcance de dicha limitación, la Corte usa los estándares normativos y jurisprudenciales desarrollados no solo en el sistema interamericano, sino también en el europeo ${ }^{88}$.

\section{d) Prohibición de tortura}

Otro aspecto interesante en la jurisprudencia de las Cortes ha sido el establecimiento de mínimos de actuación para el Estado que están determinados por sus obligaciones internacionales. Así, por ejemplo, en el año 2013, la Corte de Apelaciones de Valdivia ${ }^{89}$ constató los malos tratos que habían sufrido los internos del Centro Penitenciario de Llancahue (Valdivia) y declaró que se habían infringido la Convención contra la Tortura y Otros Tratos Crueles, Inhumanos o Degradantes (en adelante, CAT). Como consecuencia de esta infracción, la Corte acoge el recurso e indica que Gendarmería "en el futuro deberá tratar dignamente a los internos y cumplir estrictamente lo establecido en las leyes, la Constitución Política del Estado y en los tratados Internacionales de Derechos Humanos, especialmente lo dispuesto en la Convención Contra la Tortura" 90.

En este caso es relevante que se calificara los actos sufridos por los internos como tratos crueles, inhumanos o degradantes sobre la base de la tipificación que se realiza en la CAT, considerando que en Chile, a la fecha del fallo, no existía una tipificación de la tortura que se conforme a las convenciones internacionales. Además, esto permitió a la Corte cumplir con una función preventiva, al ordenar a Gendarmería a cumplir estrictamente lo establecido en la Constitución y en los tratados internacionales y, con ello, ir más allá del caso concreto, previniendo futuras violaciones de derechos humanos ${ }^{91}$.

De esta forma, el DIDH en estos casos ha servido para dotar de contenido a la obligación estatal de prohibir prácticas violatorias de la integridad personal

\footnotetext{
88 Mismo razonamiento se encuentra, entre otras, en la sentencia del máximo tribunal para la causa rol No 223-2017, 9.05.17 y para el voto de minoría del ministro Muñoz en las sentencias roles No 41-2017 y No 87876-2016.

89 Corte de Apelaciones de Valdivia, rol No 8-2013, 13.03.13.

90 Ibídem, considerando 21.

91 En el mismo sentido: Corte de Apelaciones de Antofagasta, rol No 68-2013, 7.12.13.
} 
de las persona sujetas a su control en los recintos penitenciarios y ordenar a las autoridades administrativas que garanticen el derecho a la integridad personal consagrado en la CAT. Claramente, hay una aplicación directa y sustantiva del $\mathrm{DIDH}$, en tanto, no se utiliza la CAT como elemento referencial o complementario, sino que se considera directamente violado y, por tanto, amplía la normativa reglamentaria para resolver una acción constitucional particular de personas privadas de libertad, como es la de habeas corpus.

\subsection{Mujeres $^{92}$}

Sobre derechos humanos de las mujeres en Chile ${ }^{93}$, hay un marco normativo compuesto por dos principales áreas temáticas: violencia contra las mujeres y normas en el ámbito laboral. Recientemente podemos incorporar como área los derechos sexuales y reproductivos, con la promulgación de la ley de despenalización de la interrupción voluntaria del embarazo en tres causales ${ }^{94}$.

Con relación a la violencia, la Ley No 20.066 fue promulgada con el propósito de dar cumplimiento a las obligaciones que el Estado contrajo al ratificar la Convención de Belém do Pará. En este sentido, dicha ley consagra la violencia contra la mujer como un problema de DD.HH. y establece la obligación de garantizar ciertos derechos que deberán ser cumplidos a través de políticas públicas. En el ámbito laboral encontramos las normas referidas al fuero maternal y la Ley No 20.348 sobre igualdad de remuneraciones. Ambos cuerpos normativos han sido considerados como insuficientes para combatir la discriminación que se da respecto de las mujeres en el ámbito laboral95.

A continuación, veremos si es que esta normativa se ha visto complementada o favorecida por la incorporación de normas de tratados sobre derechos humanos, con el objetivo de identificar las potencialidades de la complementariedad entre ambos cuerpos normativos para dar una protección más efectiva

\footnotetext{
92 Este apartado se ha realizado tomando como referencia parte de la investigación realizada por Camila Troncoso en su Memoria para optar al Grado de Licenciada en Ciencias Jurídicas y Sociales, véase: TronCOSO (2016) y que fue realizada en el contexto de este proyecto de investigación.

93 Aunque toda la normativa de derechos humanos puede tener un impacto específico en su ejercicio por parte de las mujeres, nos referimos a normativa dictada para hacer frente a situaciones que requieren una aproximación específica por las particularidades de la discriminación que sufren las mujeres.

94 Ley No 21.030 promulgada el 14 de septiembre de 2017.

95 Cámara de Diputados de Chile (2013) y DT (2011), pp. 29-30.
} 
a los DD.HH. de las mujeres en Chile. Como veremos, en el caso nacional los problemas no solo están dados por la insuficiencia de la legislación, sino también por la falta de incorporación de una perspectiva de género al momento de juzgar.

\section{a) Ámbito laboral}

En las sentencias analizadas en el ámbito laboral, la utilización del DIDH de las mujeres dista de ser una aplicación sustantiva que utilice los estándares establecidos internacionalmente y la perspectiva de la judicatura está fuertemente influida por estereotipos de género a la hora de interpretar-inclusive- la normativa internacional ${ }^{96}$. Por ejemplo, en una de las primeras sentencias analizadas en el período, sobre la autorización para desaforar a la trabajadora embarazada, la argumentación se fundamenta en el inciso $2^{\circ}$ del artículo 19 No 1 de la Constitución de la República y el inciso $4^{\circ}$ del artículo $1^{\circ}$, referidos a la protección de la vida del que está por nacer, lo que es utilizado por la Corte de Apelaciones de Santiago para realzar el "superior respeto al insustituible rol procreador del género femenino, al que el conglomerado social todo ha de prodigar-icómo no la judicatura!- condiciones de desarrollo espiritual y material plenamente respetuosas de su sagrada condición engendradora, al modo como perentoriamente manda el inciso cuarto del artículo $1^{\circ}$ de la misma ley primera" 97 . Luego de mencionar la legislación aplicable ${ }^{98}$ (donde se incorporan las normas internacionales, entre ellas, la Cedaw y los pactos OIT referidos a la materia), la Corte señala cuál es a su juicio la discusión de fondo, el enfrentamiento de dos intereses en juego: por un lado, el interés de un individuo en poner término a una relación de dependencia laboral, y, por otro, el interés por asegurar y mantener el "superior fin procreador" de la mujer trabajadora, el cual identifica como un fin de la sociedad en su totalidad 9 .

\footnotetext{
96 Sobre estereotipos de género no se han realizado estudios desde la perspectiva del análisis jurisprudencial, destacando únicamente el análisis realizado por Casas y González en relación a la jurisprudencia del Tribunal Constitucional de Chile, véase CASAS y GonZÁlez (2012). En el ámbito internacional, destaca el estudio de COOK y CUSACK (2010), que es un referente en la aplicación del marco teórico de los estereotipos de género en el ámbito jurisdiccional.

97 Corte de Apelaciones de Santiago, rol No 1458-2007, 9.11.07, considerando 7.

98 Ibídem, considerando 10.

99 Ibídem, considerando 11.
} 
Esta sentencia es muy buen ejemplo del impacto que tiene para el Derecho quedar atrapado en una concepción estereotipada de las mujeres y no asumir una perspectiva de género ${ }^{100}$. El “interés" del que habla la sentencia no busca cautelar los derechos de la mujer como persona individual, sino que busca proteger la maternidad, con el fin de salvaguardar la vida que está por nacer ${ }^{101}$. La mujer es vista sólo en su rol "procreador", no haciendo mención a sus derechos como tal; y, si bien, los derechos mencionados de la Cedaw hacen referencia al derecho de la mujer a la igualdad en el empleo prohibiendo el despido por razones de embarazo o licencia y la obligación del Estado de implantar licencias por maternidad, el enfoque que asume la sentencia está dado por la protección al que está por nacer, lo que se ve reflejado en la utilización de normas que aseguran los derechos de niños/as a la igualdad, a que se respete su interés superior, y a eliminar la mortalidad infantil.

También en materia de fuero laboral, otro caso controvertido lo podemos encontrar en un fallo emitido por la Corte de Apelaciones de San Miguel en el año $2012^{102}$, donde se analiza directamente si las normas internacionales sobre DD.HH. son aplicables y qué rol estas tienen en la controversia. La recurrente, frente a una sentencia que había acogido la solicitud de desafuero por parte del empleador, indica que en el caso concreto se habían vulnerado las normas constitucionales e internacionales que garantizan la protección de la maternidad, y que, entre la protección de la maternidad y la libertad contractual, debe primar la primera. En este sentido, el Tribunal debe cerciorarse no sólo de que concurra una de las causales del artículo 174 del Código del Trabajo, sino además debe concurrir un elemento subjetivo, es decir, que el hecho de la maternidad no haya influido en la decisión del empleador. La Corte de Apelaciones de San Miguel, desestimando la pertinencia de aplicar la normativa internacional en el caso, indica que dicho tribunal "no puede pasar por sobre la interpretación literal de

100 Un buen ejemplo de lo que implica juzgar con perspectiva de género lo encontramos en el Protocolo elaborado por la Suprema Corte de Justicia de México. Esta perspectiva invita a los juzgadores a incorporar en sus labores de argumentación jurídica un análisis de los posibles sesgos discriminatorios que, de manera implícita o explícita, pueden estar contenidos en la ley o en la aplicación de la misma. Véase: SCJN (2015).

101 En el mismo sentido, véase: Corte de Apelaciones de Santiago, rol No 1826-2012, 22.03.13. Esto se enmarca en una lógica patriarcal, que sólo considera a las mujeres en tanto su "función reproductora", estableciendo una serie de "protecciones" para las mujeres, que realmente salvaguardan otros intereses (como el aseguramiento de la paternidad, o protecciones para las futuras generaciones, pero no protecciones a la mujer en tanto persona), véase: FACIO y Fries (1999), p. 59.

102 Corte de Apelaciones de San Miguel, rol No 260-2012, 7.08.12. 
dichas normas, las que estiman que es procedente la interpretación otorgada por el sentenciador" 103 .

Un cambio de estas tendencias neutralizadoras del rol del DIDH lo encontramos en el año 2015 por parte de la Corte Suprema ${ }^{104}$. Esta sentencia de unificación de jurisprudencia, resuelve un recurso interpuesto ante el rechazo de la demanda que solicitaba autorización judicial para desaforar a una trabajadora embarazada, por existir un contrato de plazo fijo. La Corte Suprema hizo un análisis de la maternidad, señalando que esta se encuentra protegida por normativa internacional y por normativa interna, tanto constitucional como legal en el Código del Trabajo en sus artículos 201 y siguientes. Luego, realiza un análisis del artículo 174 estableciendo que es una facultad del juez analizar los elementos objetivos y subjetivos que pueden estar tras la decisión de desaforar. En este sentido, la circunstancia de que exista un contrato a plazo fijo no es lo único relevante, sino también deben analizarse circunstancias subjetivas.

Lo relevante de este enfoque es que aclara la obligatoriedad que tienen los/as jueces/zas de realizar su análisis considerando el DIDH, que es incorporado en función del artículo $5^{\circ}$ de la Constitución Política de la República. En esta sentencia, encontramos que el derecho internacional sirve para interpretar una institución jurídica y determinar su alcance, otorgando criterios al juzgador para valorar la concurrencia de circunstancias objetivas y subjetivas para permitir o denegar un desafuero ${ }^{105}$.

Un último caso en materia laboral, que revela el potencial de la aplicación de las normas del DIDH y las consecuencias que tiene su no aplicación, lo encontramos en materia de desigualdad salarial entre hombres y mujeres. En uno de los pocos casos referidos a la aplicación de la Ley No 20.348 sobre igualdad de remuneraciones ${ }^{106}$, la recurrente invocó la Cedaw, el Convenio Internacional de la OIT No 111, la DUDH y el PIDCP, para establecer como principio la igualdad de remuneraciones entre hombres y mujeres, y que este caso particular se vería vulnerada ya que la recurrente -ejerciendo el mismo trabajo que el hombre, gana un $88 \%$ menos. La empresa justifica esta situación debido a que

103 Ibídem, considerando 7.

104 Corte Suprema, rol No 8891-2014, 15.01.15.

105 Ibídem, considerando 8. En el mismo sentido: Corte Suprema, rol No 4935-2017, 14.09.17, considerando 6; rol No 19354-2010, 9.04.15 y rol No 47926-2016, 13.12.16.

106 Corte de Apelaciones de Santiago, rol No 1682-2011, 10.01.12. 
la situación académica de él sería superior a la de ella (aunque dicha calificación académica no era necesaria para ejercer el cargo y tampoco se encontraba en la descripción del mismo). Pese a estos antecedentes, la Corte Suprema indica que en el caso concreto el trato diferenciado se encontraría justificado ${ }^{107}$. Si bien no está prohibido por el DIDH las diferencias remuneratorias con base en la cualificación que tengan los y las trabajadoras, la posible justificación a las diferencias realizadas en las remuneraciones puede estar escondiendo situaciones de discriminación estructural (considerando que la exigencia del título universitario no era una exigencia para desempeñar el cargo), especialmente, si consideramos el artículo 11.1.d de la Cedaw que establece el derecho a la igual remuneración entre hombres y mujeres, ante un trabajo de igual valor, y el artículo 3 del Convenio No 100 de la OIT, que señala: "Las diferencias entre las tasas de remuneración que correspondan, independientemente del sexo, a diferencias que resulten de dicha evaluación objetiva de los trabajos que han de efectuarse, no deberán considerarse contrarias al principio de igualdad de remuneración entre la mano de obra masculina y la mano de obra femenina por un trabajo de igual valor".

En definitiva, esta era una oportunidad en que la Corte podría haber desarrollado el criterio de igualdad de remuneraciones entre hombres y mujeres, que no fue aprovechada ${ }^{108}$.

\section{b) Derecho de familia}

A diferencia del ámbito laboral, en derecho de familia la jurisprudencia ha sido más receptiva a la incorporación del DIDH y su aplicación ha traído consigo avances sustantivos para interpretar una normativa que data del siglo XIX.

Un ejemplo en este sentido lo encontramos en la inaplicación que se ha dado al artículo 128 del Código Civil ${ }^{109}$ (que se entiende que está tácitamente

107 Ibídem, considerandos 5 y 6.

108 En el mismo sentido anterior, otro caso que pone de manifiesto la necesidad de incorporar en el análisis de los tribunales de justicia la dimensión estructural que está detrás de muchos casos de discriminación, lo encontramos en una resolución del año 2014 de la Corte Suprema referida también a la igualdad entre hombres y mujeres (esta vez, en relación a posibles ascensos dentro de Carabineros de Chile). En este caso, la Corte Suprema descarta la existencia de discriminación ya que utiliza solo un concepto de discriminación directa, véase: Corte Suprema, rol No 22455-2014, 30.10.14, considerandos 7 y 11.

109 Artículo 128 Código Civil: "Cuando un matrimonio haya sido disuelto o declarado nulo, la mujer que está embarazada no podrá pasar a otras nupcias antes del parto, o (no habiendo señales de preñez) antes de cumplirse los doscientos setenta días subsiguientes a la disolución o declaración de nulidad (...)”. 
derogado), por las obligaciones internacionales que ha suscrito el Estado de Chile. Así, por ejemplo, la Corte de Apelaciones de Punta Arenas ${ }^{110}$, ante la apelación de una sentencia de un juzgado de familia que negaba la autorización de segundas nupcias, inicia el análisis subrayando los orígenes y objetivos de la norma, constatando la anacronía que supone su aplicación en la actualidad dada la existencia de plena igualdad (jurídica) entre hombres, mujeres e hijos matrimoniales y no matrimoniales ${ }^{111}$. La Corte de Apelaciones contrasta el artículo 128 del Código Civil con las obligaciones internacionales contraídas por el Estado de Chile y contenidas en los pactos internacionales, realizando un ejercicio de control de convencionalidad que le permite descartar la aplicación del artículo ${ }^{112}$. Esta interpretación es además una manifestación de la interpretación evolutiva que se debe hacer de las normas e institucionales sociales para cumplir con los imperativos de la protección de los derechos fundamentales.

Siguiendo con la ruta crítica que representa este análisis (por el carácter excepcional de la aplicación del DIDH referido a los derechos de las mujeres por nuestros tribunales superiores de justicia), queremos destacar un caso donde se evidencian las posibilidades de la aplicación del DIDH (es decir, pudiendo haberse utilizado no se realizó). Se trata de un caso fallado por la Corte Suprema ${ }^{113}$ y referido al conflicto que surge entre derecho de un padre para interponer la nulidad del reconocimiento de un menor contra la prescripción de dicha institución. Lo interesante no lo encontramos en el voto de mayoría, sino en el voto del Ministro Cerda, que efectivamente apoya la decisión de la Corte pero con fundamentos basados en el DIDH de las mujeres ${ }^{114}$. En relación con los artículos 5.a y 2.c de la Cedaw, el Ministro resalta que es deber de los Estados modificar los patrones socioculturales y eliminar prácticas y costumbres basadas en estereotipos. Siendo este deber no sólo del poder legislativo, pues es también a través de los tribunales nacionales competentes que la mujer adquiere la efectiva protección de sus derechos. Se consagraría, por tanto, el deber del Poder Judicial de adoptar las medidas que sean necesarias y que estén dentro de

110 Corte de Apelaciones de Punta Arenas, rol No 116-2011, 20.01.12.

111 Ibídem, considerando 6.

112 Ibídem, considerandos 11 y 13.

113 Corte Suprema, rol No 12492-2014, 18.03.15.

114 Corte Suprema, rol No 12492-2014, 18.03.15, voto del ministro Carlos Cerda, considerando 7. 
su alcance, para eliminar la discriminación sufrida por la mujer. Se argumenta que el derecho no es una serie de compartimentos, sino que es un todo, integrado por el DIDH el cual se hace aplicable pudiendo servir como base para modificar o interpretar el derecho nacional. Así, en este caso, señala que si no se observara el derecho internacional se aplicaría la prescripción, pero que debido a la visión holística e integral que debe tener el juez, se termina incluso por derogar ciertas instituciones que inspiraron a Bello, a la luz del DIDH de los niños y las mujeres.

\section{c) Violencia contra las mujeres}

Con respecto a la violencia contra las mujeres, encontramos un caso en la Corte de Apelaciones de Punta Arenas ${ }^{115}$, donde el DIDH sirve para establecer el fenómeno de la violencia como un caso de violación de derechos humanos. Establece la Corte "que la violencia contra la mujer constituye una violación de los derechos humanos y las libertades fundamentales y le limita total o parcialmente el reconocimiento, goce y ejercicio de tales derechos y libertades (Preámbulo Convención de Belém do Pará)"116. Luego, se señalan los principales derechos garantizados en la Convención de Belém do Pará, relacionados principalmente con el derecho de toda mujer a una vida libre de violencia, no sólo en el ámbito público sino también en el ámbito privado y el respeto a su integridad física, psíquica y moral. Sobre esa base, el Tribunal reconoce el fenómeno de la violencia como aquel en que están involucrados derechos humanos, y que el Estado tiene un rol activo y fundamental en su prevención y sanción. La Corte reconoce que esto no es un problema entre dos personas, sino que es un problema de la sociedad y que las obligaciones del Estado se relacionan con prevenir, investigar y sancionar, es decir, con una obligación de garantía de los derechos efectivamente reconocidos en los tratados internacionales, como por ejemplo, actuar con la debida diligencia. Por otro lado, en la misma sentencia se hace referencia a la igualdad entre hombre y mujer en el matrimonio, utilizando el PIDCP, la CADH y la Cedaw. Lo relevante en este punto, es que se toma en consideración que durante la fase de disolución del matrimonio, también se ve reflejado el carácter abusivo y violento de la relación, y, por lo tanto, es

115 Corte de Apelaciones de Punta Arenas, rol No 28-2012, 4.05.12.

116 Ibídem, considerando 2. 
deber de los tribunales intervenir en ese momento para que las consecuencias de la violencia cesen ${ }^{117}$. En el caso, la Corte de Apelaciones, después de haber explicado latamente la violencia contra la mujer y los principios en que se funda su protección, confirma la sentencia apelada ordenando el abandono del hogar común del agresor.

Otro ejemplo de la perspectiva que consideraba la violencia contra las mujeres como una violación de DD.HH. que debe ser prevenida por el Estado, es un caso de extradición fallado por la Corte Suprema el año 2016. En este caso se solicitaba la extradición de una ciudadana a su país de origen por una demanda que existía de sustracción de menores. La Corte Suprema, acogiendo las reclamaciones de la demandada118, sostuvo que no concedería la extradición basándose en el peligro que supondría para la mujer y sus hijos su retorno ${ }^{119}$. Similares consideraciones respecto al rol del Estado en el respeto y garantía de los derechos de la mujer y la prevención de la violencia lo encontramos en un caso fallado por la Corte de Apelaciones de San Miguel ${ }^{120}$. En este caso se había denegado una querella por violencia por considerar que la Gobernación Provincial no tenía legitimidad activa, pues los hechos habían ocurrido en la "esfera privada". Sin embargo, la Corte de Apelaciones de San Miguel revoca dicha resolución y establece que, por aplicación de las obligaciones del Estado, debe admitirse a tramitación la querella ${ }^{121}$.

En estos casos, la Convención de Belém do Pará es usada sustantivamente para incorporar obligaciones adicionales al Estado vinculados al rol de garante que debe tener este para prevenir la violencia contra las mujeres (ya sea denegando una extradición que podía poner en peligro a una mujer, o investigando una denuncia de violencia).

Un buen ejemplo de las potencialidades de la utilización de la normativa y la jurisprudencia internacional en esta materia (si se le diera una aplicación sustantiva), lo encontramos en un caso fallado por la Corte de Apelaciones de La Serena ${ }^{122}$. En este caso, la Corte descarta la importancia de la dimensión

117 Ibídem, considerando 8.

118 Corte Suprema, rol No 17976-2016, 11.04.16, considerando 3.

119 Ibídem, considerando 10.

120 Corte de Apelaciones de San Miguel, rol No 1769-2016, 5.09.16.

121 Ibídem, considerandos 2 y 4.

122 Corte de Apelaciones de La Serena, rol No 516-2016, 10.01.17. 
estructural de la violencia que sufren las mujeres y la importancia de la dinámica de la violencia para efectos probatorios. No se trata de en todo caso preferir el testimonio de la víctima (como parece entender la Corte ${ }^{123}$ ), sino entender los patrones en que se da la violencia y, atendida la obligación que el Estado tiene para prevenir la violencia, disponer de otro tipo de medidas que pudieran coadyuvar para comprender el relato y determinar su veracidad, conforme a las obligaciones que ha asumido el Estado en materia de debida diligencia para enfrentar el fenómeno de la violencia ${ }^{124}$.

Un caso exitoso sobre una mejor protección de los DD.HH. de las mujeres es la sentencia dictada por la Corte Suprema en la acción de habeas corpus de Lorenza Cayuhán. El 13 de octubre de 2016 Lorenza Cayuhán fue llevada por funcionarios de Gendarmería de Chile a un centro hospitalario pues tenía 32 semanas de embarazo y presentaba signos de preeclampsia, además, tanto en la ambulancia como en el recinto hospitalario, fue mantenida con grilletes que ataban uno de sus pies a la camilla o cama. Estos actos fueron considerados por la Corte Suprema ${ }^{125}$ como injustificados, puesto que la amparada se encontraba con riesgo vital, así como su hijo, lo que permitía descartar que en esas condiciones pudiese fugarse. Frente a estos hechos el máximo tribunal declaró que Gendarmería de Chile había vulnerado los compromisos asumidos por el Estado de Chile frente a la CADH, PIDCP y la Cedaw. Para llegar a esta conclusión, la Corte Suprema desarrolla tres aspectos que nos parecen fundamentales para dar cuenta de una nueva perspectiva para abordar estas temáticas mediante la incorporación de estándares sustantivos de DIDH: incorporación de la perspectiva de género, concepto de discriminación múltiple y adopción de medidas estructurales.

En primer lugar, la Corte Suprema razona sobre la base de las obligaciones internacionales del Estado referidas a la prohibición de la violencia contra las mujeres y utiliza esta normativa para dotar de contenido al concepto de "violencia contra la mujer", para calificar el caso de Lorenza como una situa-

\footnotetext{
123 Ibídem, considerandos 5 a 8.
}

124 Una aproximación de razonamiento que nos parece adecuada en aplicación de estándares internacionales es la que desarrolla la Ministra Pinto en una prevención en un fallo de la Corte de Apelaciones de Punta Arenas, véase: Corte de Apelaciones de Punta Arenas, rol No 2-2016, 12.02.16, voto de prevención de la ministra Pinto.

125 Corte Suprema, rol No 92795-2016, 1.12.16. 
ción de violencia ${ }^{126}$. Por otra parte, resulta relevante que la Corte Suprema asuma expresamente una perspectiva de género al analizar el caso, ya que desarrolla el impacto diferenciado que tiene la violencia ejercida contra Lorenza por su condición de mujer ${ }^{127}$. La Corte Suprema razona incorporando una perspectiva de género, lo que supone considerar las particularidades de una mujer embarazada, lo que hace necesario adoptar medidas adecuadas a dicha circunstancia. El no hacerlo implicó una discriminación en razón del género para la amparada ${ }^{128}$.

Además, la Corte incorpora la categoría de la discriminación múltiple en su análisis ${ }^{129}$. En este caso la Corte Suprema reconoce que en el caso "[H]ay una situación paradigmática de interseccionalidad en la discriminación, donde se observa una confluencia de factores entrecruzados de discriminación que se potencian e impactan negativamente en la amparada, pues ésta recibió un trato injusto, denigrante y vejatorio, dada su condición de mujer, gestante y parturienta, privada de libertad y perteneciente a la etnia mapuche, lo que en forma innecesaria puso en riesgo su salud y vida, así como la de su hijo, todo ello, en contravención a la normativa nacional e internacional vigente en la materia" 130 .

En cuanto a las medidas que adopta la Corte, la sentencia entiende que el restablecimiento del imperio del derecho implica ir más allá, por ejemplo, disponiendo medidas para la corrección funcionaria. En este caso, además de ordenar a Gendarmería a ceñirse a las Reglas Mínimas de las Naciones Unidas para el tratamiento de los reclusos, dispone en general que se deberán revisar y adecuar los protocolos "conforme a la normativa Internacional suscrita por Chile relativa a mujeres privadas de libertad, embarazadas o con hijos lactantes, así como a

126 Ibídem, considerando 13.

127 Ibídem, considerando 14.

128 En concreto, para determinar cuál debe ser el trato que deben recibir las mujeres embarazadas y privadas de libertad, la Corte Suprema no solo recurre a tratados internacionales, sino también a Reglas de Naciones Unidas y a Observaciones de organismos de protección que son específicas en la materia. Esto es relevante considerando que los mandatos de la legislación nacional son genéricos y estas reglas y observaciones ayudan a dar un contenido específico a las obligaciones.

129 Esta categoría, que alude a la intersección de más de un factor de discriminación (en este caso, género y etnia) respecto de un individuo permite analizar las causas que potencian la exclusión en el ejercicio de derechos. Ejemplos de esta perspectiva los encontramos en los casos Fernández Ortega, Rosendo Cantú y González Lluy ante la Corte Interamericana de Derechos Humanos.

130 Corte Suprema, rol No 92795-2016, 1.12.16, considerando 15. 
aquella relativa a la erradicación de todas las formas de violencia y discriminación en contra de las mujeres"131.

En este sentido, esta sentencia, además de aportar elementos relevantes para ejemplificar qué significa juzgar con perspectiva de género, nos pone en alerta sobre los desafíos que enfrenta la autoridad frente a la discriminación estructural. La articulación entre los diversos poderes públicos está en la base de los desafíos en la materia.

\section{Evaluación del proceso de recepción del Derecho Internacional \\ De los Derechos Humanos y los Caminos Que el SisTema nORMativo PERMITE PARA MEJORAR LA PROTECCIÓN}

A continuación, realizamos una breve valoración de la protección jurisdiccional de derechos humanos de grupos en situación de discriminación estructural y proponemos algunos cursos de acción a partir de la experiencia comparada e internacional para una mejor protección jurisdiccional de sus derechos humanos.

\subsection{Evaluación de la protección jurisdiccional de grupos en situación de discriminación estructural}

Conforme al análisis de la incorporación sustantiva del DIDH en casos de grupos que se encuentran en situación de discriminación estructural, podemos establecer que la jurisprudencia oscila entre una incorporación sustantiva relevante de estándares de derechos humanos basados en el DIDH (como es el caso de los DD.HH. de las personas migrantes) y una incorporación meramente referencial o neutralizadora (como es el caso de los derechos humanos de las mujeres).

En materia de población migrante, los usos evidenciados del DIDH muestran la capacidad del DIDH de complementar aquellos aspectos donde no existe regulación, o bien es insuficiente (como por ejemplo, en cuanto a los estándares de debido proceso en materia migratoria), o profundizando la protección (por ejemplo, enfatizando las obligaciones del Estado en relación con la protección de la familia a la luz de la Convención sobre los Derechos del Niño). Esto es importante cuando nos encontramos frente a normativas que son altamente

131 Ibídem, parte resolutiva. 
deficientes desde la perspectiva del enfoque de derechos humanos, como ocurre en el caso de la migración. Aunque en los últimos años se ha incorporado al razonamiento estándares que no solo se encuentran en los tratados (como Observaciones Generales de Naciones Unidas), aún las Cortes nacionales no dan el paso a considerar, por ejemplo, la jurisprudencia de la Corte Interamericana de Derechos Humanos y sus opiniones consultivas. A este respecto la incorporación sustantiva de estos estándares como criterios interpretativos fortalecería la protección nacional, teniendo en cuenta que hay aspectos que se encuentran altamente desarrollados en esta sede, por ejemplo, las garantías del debido proceso en materia migratoria.

En materia de pueblos indígenas, un desafío pendiente en esta materia es la prueba de la costumbre indígena en juicio y avanzar hacia el reconocimiento de las formas propias de justicia de los pueblos indígenas. El problema en esos casos no ha sido de incorporación sustantiva de las normas Convenio, sino en la manera en que los operadores de justicia siguen operando bajo paradigmas monoculturales. Aquí el DIDH puede desempeñar un rol relevante, por ejemplo, mediante la incorporación en el razonamiento judicial de reglas que coadyuvan en la identificación de prejuicios culturales y en el desarrollo de parámetros de interpretación que permitan compatibilizar tensiones entre los ordenamientos jurídicos. Por su parte, la inclusión de las normas del Convenio 169 también ha significado un gran aporte para la protección del patrimonio cultural indígena y para la ampliación del concepto de tierras hacia el concepto de territorio (hay una interpretación de la normativa nacional a partir del Convenio 169 de la OIT que permite hacer una lectura de la normativa en clave colectiva). Asimismo, su inclusión como parámetro de legalidad para la actuación de la fuerza pública es un avance no solo para el amparo de la libertad y seguridad en casos concretos, sino también para fundar el diseño de protocolos y normativas que garanticen los DD.HH. de los pueblos indígenas en contextos de violencia. En materia de consulta, la incorporación sustantiva del DIDH marca definitivamente un cambio de paradigma respecto de la participación de los pueblos indígenas en Chile. Con la introducción de los nuevos reglamentos de consulta, el Convenio puede ser utilizado para llenar los vacíos de la normativa o interpretarla conforme a las obligaciones internacionales. La jurisprudencia reseñada muestra que la aplicación de buena fe del Convenio en el razonamiento judicial permite este ejercicio. Las críticas que se realizan a la deficiente técnica normativa y de legitimidad de los nuevos reglamentos deben seguir instalándose en el debate 
con el objeto de llegar a un reconocimiento del derecho a la consulta conforme a los estándares internacionales, pero en la experiencia práctica el Convenio puede ser utilizado como una herramienta normativa que mejora y complementa los reglamentos.

Las personas privadas de libertad constituyen un grupo de especial preocupación por parte del Derecho Internacional atendida la situación de vulnerabilidad de sus derechos por la situación de dependencia del Estado en la que se encuentran las personas en custodia del Estado. En cuanto a la seguridad de las personas privadas de libertad, claramente se establece el rol de garante de la autoridad administrativa, siendo relevante para la argumentación del tribunal los estándares desarrollados por la Corte Interamericana en la materia. Esta visión sobre la seguridad también abarca la protección de derechos al interior de los recintos penitenciarios, para lo cual se han desarrollado estándares exigentes en materia de debido proceso para la aplicación de sanciones; los límites a la aplicación de sanciones de adolescentes privados de libertad o la aplicación de la norma más favorable en materia de beneficios penitenciarios. En materia de prohibición de tortura en recintos penitenciarios ha habido una utilización efectiva del DIDH para fijar un parámetro más estricto sobre el deber de cuidado por parte de la autoridad administrativa. Se han utilizado los estándares internacionales para poder dar concreción a esta prohibición frente a una normativa muy genérica en la materia. En cuanto a los tratos discriminatorios por identidad de género, sí se ha usado el DIDH (normas contenidas en tratados, principios, jurisprudencia) para darle contenido a este límite al trato de la autoridad a las personas privadas de libertad. Lo mismo se ha hecho para dar efectividad al derecho a sufragio de que son titulares las personas privadas de libertad.

Finalmente, respecto de los DD.HH. de las mujeres, se presentan los mayores déficits de recepción sustantiva del DIDH en la jurisprudencial nacional. Del análisis de las sentencias que utilizan DIDH de las mujeres en materia laboral, encontramos que se refieren a dos ámbitos: protección de la maternidad e igualdad de remuneraciones. En cuanto al primer ámbito, no se aprecia que los tribunales superiores de justicia utilicen sustantivamente el DIDH de las mujeres en la resolución de los casos; es más, cuando menciona a los Convenios de la OIT y a la Cedaw, lo realiza siempre considerando un interés que no es el de la mujer, sino el interés del niño o "de la sociedad", es decir, se basa en una visión de la mujer/madre y no en la mujer/persona, primando recurrentemente intereses diversos a los de la mujer. Llama la atención que no se consideren los 
patrones estructurales que pueden estar detrás de la discriminación en razón del género. Sin embargo, hay un caso que muestra una utilización sustantiva del DIDH de las mujeres y que tiene como efecto una mayor protección de los derechos de la mujer involucrada, referida a la derogación tácita del artículo 128 del Código Civil, precisamente porque es contrario a las obligaciones establecidas en las convenciones internacionales, y que, en caso de no ser derogado, perpetúa la discriminación contra la mujer. En materia de violencia, la conclusión ha sido que, en general, destaca la ausencia de utilización sustantiva del DIDH de las mujeres debido a la preeminencia dada a la legislación nacional, bajo el argumento de la suficiencia del derecho nacional para analizar una determinada situación y que esta estaría inspirada a su vez en las obligaciones internacionales que ha asumido el Estado de Chile. Cuando se ha hecho uso, ha sido para ampliar los alcances de la violencia a la disolución del matrimonio, vinculando violencia con discriminación; asimismo, para establecer medidas especiales de protección o estableciendo obligaciones de protección de derechos de mujeres en situación de violencia.

Como vemos, los déficits de aplicación de los estándares internacionales por parte de la jurisprudencia nacional están más vinculados con una dimensión de cultura jurídica recelosa de utilizar el DIDH para dar efectividad a los derechos y así cumplir con las obligaciones internacionales en un marco de coherencia normativo. Cuando los tribunales logran ampliar su mirada, como en materia migratoria, los déficts normativos pueden ser superados.

Los déficits destacados no solo dan cuenta de una escasez cultural en materia de recepción del DIDH en el ámbito interno, sino también da cuenta de una mirada restrictiva de los derechos humanos ${ }^{132}$. Por tanto, el principal aporte del DIDH es la configuración de una interpretación de los derechos fundamentales que da cuenta de una mirada amplia del contenido y alcance de estos derechos e involucra a los poderes judiciales en la actividad de los órganos políticos ${ }^{133}$.

132 El profesor Roberto Saba ha señalado, en referencia a la experiencia argentina, que una visión restrictiva de los derechos humanos considerando los derechos solo como libertades negativas y que conciben su labor como una función que no puede contraponerse con la de los poderes políticos, lleva a atender sólo los casos individuales, pues el juicio sobre casos de tipo colectivo se percibe como una decisión general que únicamente compete a los poderes políticos del Estado (SABA, 2016: 256).

133 Los alcances de este desarrollo amplio de los derechos fundamentales, ver NASH (2010). 


\subsection{Algunos caminos para mejorar la protección jurisdiccional de derechos de grupos en situación de discriminación estructural}

Recordemos que, como veíamos a propósito del concepto de violaciones estructurales a los derechos humanos, estos casos requieren respuestas más complejas por parte de la judicatura para garantizar los DD.HH. en condiciones de igualdad. En efecto, en estos casos es necesario recalcar que el Estado debe velar por realizar una interpretación de la situación y de las normas que considere la situación específica en que se encuentran dichas personas para garantizar un acceso a la justicia igualitario. Esta constatación, en la perspectiva comparada ${ }^{134}$ y en los órganos de protección internacional ${ }^{135}$, al menos dos tipos de aproximaciones: a) el desarrollo de "sentencias estructurales" que permiten enfrentar los aspectos de fondo de las situaciones de violaciones estructurales de DD.HH, particularmente, cuando la autoridad ha omitido sus deberes constitucionales de respeto y garantía de derechos humanos sin discriminación y, b) una interpretación de la normativa que considere el contexto y las particularidades de los titulares de derechos humanos.

Los grandes desafíos en Chile para el futuro de una construcción robusta de los derechos humanos, con base en su faceta de origen nacional (constitución, leyes) e internacional (tratados, costumbre, jurisprudencia internacionales), no son normativos, sino que de enfoque hermenéutico. La normativa constitucional, con sus deficiencias, permite un enfoque estructural derechos humanos. En efecto, el art. 20 de la Constitución está estructurado sobre una base amplia, que garantiza el ejercicio de ciertos derechos consagrados constitucionalmente frente a su "privación, perturbación o amenaza". Esto permite construir una protección robusta de los derechos, en tanto se garantiza su protección constitucional frente a diversas formas de violación de los mismos, esto es, se garantiza la actuación jurisdiccional frente a cualquier actuación que impida su pleno ejercicio. Asimismo, la Constitución permite una protección eficaz a través de las medidas que la autoridad judicial puede disponer frente a estas afectaciones al

134 Un estudio sobre esta aproximación por parte de la jurisprudencia para enfrentar casos de discriminación estructural, en: NASH y NúŃEZ (2015) (en relación con la jurisprudencia latinoamericana) y BONILLA (2013) (con respecto al denominado "Sur Global").

135 Un análisis de la aproximación estructural en la jurisprudencia interamericana, véase: NASH y NúNEZ (2015) y, desde la perspectiva conceptual, véase: SALOMÉ (2017). 
ejercicio de los derechos ${ }^{136}$. Sin duda, que esta formulación de las "providencias" permite un amplio espectro de medidas vinculadas con las diversas formas de afectación y, asimismo, con las diferentes facetas de cada derecho fundamental en tanto estándar normativo complejo. La Constitución no limita las medidas, sino que las deja a criterio de la autoridad judicial ("las providencias que juzgue necesarias") y les da un sentido dual: para restablecer el imperio del derecho y asegurar la protección del afectado. En esta línea, sería posible que, al objeto de "asegurar la protección del afectado", también se dicten medidas que se dirijan a las causas de las violaciones y no solo resuelvan el caso concreto. En segundo lugar, en cuanto a los "actos u omisiones arbitrarios o ilegales" que sean base de una violación de derechos fundamentales, estos actos $\mathrm{u}$ omisiones pueden ser constitutivos de una "situación" de vulneración de derechos fundamentales. De ahí que sea plenamente procedente que, en casos de situaciones de violación de derechos fundamentales, se recurra a la protección constitucional. Estas situaciones no son sino un conjunto de actos u omisiones y, por tanto, no hay una contradicción entre la redacción constitucional y la protección a través de este recurso frente a situaciones de violación de derechos fundamentales ${ }^{137}$.

En cuanto al enfoque hermenéutico a partir de estándares internacionales para enfrentar violaciones estructurales, este debe basarse en el principio de eficacia de la protección. En el caso de la judicatura nacional un enfoque adecuado es central. Para la judicatura, una manera eficaz de proteger los derechos en condiciones de igualdad y no discriminación debe consistir en superar el paradigma de la neutralidad en la interpretación, incorporando al ejercicio hermenéutico la situación de vulnerabilidad que afecta a las víctimas y los elementos culturales preponderantes. La consideración de estos elementos permite que la aplicación neutral de las normas, que genera situaciones de discriminación, se atenúe y vaya en la línea de una interpretación evolutiva de los derechos que permita dar concreción al principio de universalidad. Una adecuada lectura de la realidad, con las complejidades en la construcción de violaciones de DD.HH. donde

136 La Constitución dispone que "[l]a Corte de Apelaciones respectiva] adoptará de inmediato las providencias que juzgue necesarias para restablecer el imperio del derecho y asegurar la debida protección del afectado".

137 Esta perspectiva no implica eliminar la dimensión política vinculada a la problemática (como comúnmente se suele destacar en relación a las sentencias estructurales), sino que, por el contrario, justamente ayuda a movilizar -mediante el impulso jurisdiccional- a aquellas autoridades que, debiendo actuar, no lo han hecho (SABA, 2016). 
concurren elementos institucionales y culturales, sumada a una búsqueda de medidas que transformen la realidad y se dirijan eficazmente a erradicar dichas violaciones, son la base de decisiones judiciales basadas en un enfoque de derechos humanos ${ }^{138}$. Dentro de las medidas adecuadas para favorecer este tipo de enfoques, se encuentra la capacitación de funcionarios/as judiciales para incorporar la perspectiva de género o cultural en el análisis de $\operatorname{casos}^{139}$.

\section{Conclusiones}

Chile se ha comprometido a la recepción del DIDH a nivel interno a través de su ratificación de un nutrido cuerpo normativo internacional que se ha incorporado al sistema normativo internacional y ha pasado a ser obligatorio para todas las autoridades internas, incluidas las judiciales. En el proceso de recepción sustantiva, en tanto una aplicación efectiva de dichos estándares en los casos nacionales, al igual que en otros ámbitos, en materia de grupos en situación de discriminación en Chile, los usos del DIDH han sido para concretar principios constitucionales, ampliar el contenido y alcance de derechos, llenar lagunas normativas, inaplicar normas y transformar conductas funcionarias.

Si bien este es un proceso en curso, aún no es un proceso eficaz. En efecto, la aplicación directa del DIDH ha servido para garantizar derechos de personas en migración; ampliar la protección de pueblos indígenas, considerando su identidad cultural; darle un nuevo enfoque -correctivo- a la protección de los derechos humanos de las mujeres; o cambiar el paradigma para evaluar el rol de garante de derechos del Estado respecto de las personas bajo su custodia. Mas, pese

138 En el caso Atala e hijas vs. Chile, la Corte Interamericana le indicó al Estado de Chile su obligación de adoptar medidas de transformación: "La Corte resalta que algunos actos discriminatorios analizados en capítulos previos se relacionaron con la reproducción de estereotipos que están asociados a la discriminación estructural e histórica que han sufrido las minorías sexuales (supra párr. 92), particularmente en cuestiones relacionadas con el acceso a la justicia y la aplicación del derecho interno. Por ello, algunas de las reparaciones deben tener una vocación transformadora de dicha situación, de tal forma que las mismas tengan un efecto no solo restitutivo sino también correctivo hacia cambios estructurales que desarticulen aquellos estereotipos y prácticas que perpetúan la discriminación contra la población LGTBI. En esta línea a continuación se analizarán las solicitudes de la Comisión y los representantes". (Corte IDH. Caso Atala Riffo y niñas vs. Chile, párr. 267).

139 Un buen ejemplo de política judicial en este sentido lo impulsó la Suprema Corte de Justicia de la Nación en México mediante la elaboración de "Protocolos" de actuación para afrontar casos que involucran a ciertos grupos en situación de vulnerabilidad, facilitando la labor de los juzgadores mediante la sistematización de criterios interpretativos. Un esfuerzo similar se está comenzando a desarrollar en Chile en la reciente creada Dirección de Estudios de la Corte Suprema. 
a un diseño normativo que se lo permite, las medidas aún no son eficaces para resolver los temas de fondo y se han quedado en soluciones de casos concretos.

Frente a los casos de discriminación estructural, que requieren una respuesta más compleja que el caso individual y en eso aún ha sido insuficiente el uso del DIDH. Si bien en algunos casos ha sido útil para mejorar la protección de derechos humanos, factores culturales y no normativos han impedido desarrollar consistentemente una interpretación jurisdiccional que dé efectividad a los derechos de grupos en situación de discriminación estructural, no ha permitido el pleno cumplimiento de las obligaciones internacionales del Estado y no ha dado coherencia al sistema normativo complejo construido a partir de la recepción formal del DIDH en Chile.

Para mejorar la respuesta judicial, el sistema interamericano de DD.HH., y particularmente la jurisprudencia de la Corte IDH, aporta algunos elementos que debieran ser considerados en Chile. La experiencia comparada, tanto nacional como internacional, aporta un amplio desarrollo de lo que se conoce como "sentencias estructurales" que permiten enfrentar los aspectos de fondo de las situaciones de violaciones estructurales de DD.HH., particularmente, cuando la autoridad ha omitido sus deberes constitucionales de respeto y garantía de derechos humanos sin discriminación. Asimismo, enfrentar estas situaciones debe hacerse considerando el contexto y las particularidades de los titulares de derechos humanos. El denominador común es la obligación estatal de adoptar medidas correctivas para superar situaciones de discriminación que afectan el pleno ejercicio del derecho a un acceso a la justicia en condiciones de igualdad.

\section{BiBLIOGRAFÍA}

\section{MONOGRAFÍAS Y ARTÍ́CULOS ACADÉMICOS}

Abramovich, Víctor (2009). "De las violaciones masivas a los patrones estructurales: nuevos enfoques y clásicas tensiones en el sistema interamericano de derechos humanos", en Revista Sur (No 11), pp. 7-39.

Aguiló, Pedro; Milos, Catalina y Nash, Claudio (2013). Personas privadas de libertad y medidas disciplinarias en Chile: análisis y propuestas desde una perspectiva de derechos humanos (Santiago, Centro de Derechos Humanos Universidad de Chile).

Aguiló, Pedro; Bascur, María Luisa y Nash, Claudio (2014). Corrupción y derechos humanos: una mirada desde la jurisprudencia de la Corte Interamericana 
de Derechos Humanos (Santiago, Centro de Derechos Humanos Universidad de Chile).

Bertini, Leonello y Yáñez, Nancy (2013). "Pluralismo jurídico: derecho indígena y justicia nacional", en Anuario de Derechos Humanos (No 9), pp. 151-160. Bonilla, Daniel (Ed.) (2013). Constitutionalism of the Global South (New York, Cambridge University Press).

Casas, Lidia y GonZÁlez, Juan Pablo (2012). "Estereotipos de género en sentencias de Tribunal Constitucional”, en Anuario de Derecho Público, pp. 250-272.

Carmona, Cristóbal (2015). "Hacia una comprensión 'trágica' de los conflictos multiculturales: acuerdos reparatorios, violencia intrafamiliar y derecho propio indígena”, en Revista Chilena de Derecho, Vol. 42 (No 3), pp. 975-1001. Contreras, María Fernanda (2018). La desnaturalización de la obligación internacional de consulta indígena como derecho humano. Memoria para optar al Grado de Licenciado(a) en Ciencias Jurídicas y Sociales (Santiago, Universidad de Chile).

СоOK, Rebecca у CusACK, Simone (2010). Estereotipos de género: perspectivas legales transnacionales (Bogotá, ProFamilia).

CourTis, Christian (2009). "Apuntes sobre la aplicación del Convenio 169 de la OIT sobre pueblos indígenas por los tribunales de América Latina”, en Revista Sur (No 10), pp. 53-78.

Didier, Marcel y Godoy, Rodrigo (2014). "Comentarios de jurisprudencia de la Corte Suprema y el Tribunal Constitucional sobre derechos humanos de las personas migrantes durante el año 2013", en Anuario de Derechos Humanos (No 10), pp. 769-782.

FACIO, Alda y Fries, Lorena (1999). "Feminismo, género y patriarcado", en Género y Derecho (Santiago, LOM), pp. 21-60.

Fuenzalida, Sergio (2015). "Desarrollo de la jurisprudencia en Chile sobre la consulta indígena: los casos del Tribunal Constitucional y la Corte Suprema”, en Revue Québécoise de Droit International, pp. 149-177.

GALDÁmEZ, Liliana (2013). "Comentario jurisprudencial sobre la sentencia del Tribunal Constitucional, rol No 2273-12-INA sobre inaplicabilidad de normas del D.L. No 10.094 que establece normas sobre los extranjeros en Chile y las matizaciones de la rol No 2257-12-INA", en Revista Estudios Constitucionales (No 2), pp. 769-782.

Henríquez, Miriam (2013). ¿Hacia una ampliación del habeas corpus por la Corte Suprema?, en Revista de Derecho UCN (No 1), pp. 421-437. 
Henríquez, Miriam (2014). "El habeas corpus como recurso idóneo para garantizar la libertad personal de los migrantes. Análisis jurisprudencial 2009-2013”, en Ius et Praxis (No 1), pp. 365-375.

Henríquez, Miriam y Morales, Mariela (Coords.) (2017). El control de convencionalidad: un balance comparado a 10 años de Almonacid Arellano vs. Chile (Santiago, Der Ediciones).

Horvitz, María Inés y López, Julián (2002). Derecho procesal penal chileno. Tomo I. (Santiago, Editorial Jurídica).

Kendal, Stephen (2010). Tutela judicial efectiva en la relación jurídica penitenciaria (Santiago, Librotecnia).

Meza-Lopehandía, Matías (2016). "La jurisprudencia del multiculturalismo en Chile: la consulta previa indígena ante tribunales", en Revista de Ciencias Sociales (No 69), pp. 13-52.

NASH, Claudio (2010). La concepción de derechos fundamentales en Latinoamérica: Tendencias jurisprudenciales. (México D.F., Editorial Fontamara).

NASH, Claudio (2013). "Control de convencionalidad. Precisiones conceptuales y desafíos a la luz de la jurisprudencia de la Corte Interamericana de Derechos Humanos", en Anuario de Derecho Constitucional Latinoamericano (año 19), pp. 489-509.

NaSH, Claudio y NúNEz, Constanza (2015). Tutela judicial efectiva de los derechos fundamentales en Latinoamérica (México D.F., Ubijus).

NASH, Claudio y NúÑEZ, ConstanzA (2017). "Los usos del Derecho Internacional de los Derechos Humanos en la jurisprudencia de los Tribunales Superiores de Justicia en Chile", en Revista Estudios Constitucionales (No 1), pp. 15-54.

NúñEz, Constanza (2016). Control de convencionalidad: teoría y aplicación en Chile (Santiago, Librotecnia).

PALMA, Rosario y SANDrini, Renata (2014). "Mujer mapuche y retos de la justicia intercultural: aplicación del derecho propio indígena en delitos de violencia intrafamiliar", en Anuario de Derechos Humanos (No 10), pp. 151-161.

SABA, Roberto (2016). Más allá de la igualdad formal ante la ley. ¿Qué les debe el Estado a los grupos desaventajados? (Buenos Aires, Siglo Veintiuno Editores) $(E b o o k)$.

SALOMÉ, Liliana (2017). El concepto 'discriminación estructural'y su incorporación al Sistema Interamericano de Derechos Humanos. Tesina de Máster en Estudios Avanzados en Derechos Humanos Instituto de Derechos Humanos "Bartolomé de las Casas" (Madrid, Universidad Carlos III de Madrid). 
Troncoso, Camila (2016). Derecho Internacional de los Derechos Humanos de las Mujeres y su recepción por los tribunales superiores de justicia. Memoria para optar al Grado de Licenciada en Ciencias Jurídicas y Sociales Facultad de Derecho Universidad de Chile (Santiago, Facultad de Derecho Universidad de Chile).

\section{INFORMES, RESOLUCIONES Y ESTUDIOS}

Cámara de Diputados de Chile (2013). Evaluación de la Ley No 20.348 que resguarda el derecho a la igualdad de remuneraciones. Dirección de evaluación Cámara de Diputados. Santiago, [fecha de consulta: 29 de octubre de 2017]. [Disponible en: http://www.evaluaciondelaley.cl/foro_ciudadano/site/ artic/20130325/asocfile/20130325153119/informe_ley_nro_20348.pdf].

Centro de Derechos Humanos Universidad de Chile (2013). Erradicación de la violencia contra las mujeres en las Américas. Violencia contra mujeres indígenas en el marco de las relaciones familiares: pautas para decidir la procedencia de acuerdos reparatorios, Santiago, [fecha de consulta: 29 de octubre de 2017]. [Disponible en: http://repositorio.uchile.cl/handle/2250/142498].

Centro de Derechos Humanos Universidad de Chile (2014). Derechos Humanos y pueblos indígenas en Chile. Análisis jurisprudencial para procesos de consulta en el marco del Convenio 169 de la OIT, Santiago, [fecha de consulta: 29 de octubre de 2017]. [Disponible en: [http://repositorio.uchile.cl/ handle/2250/142688].

Centro de Derechos Humanos Universidad de Chile (2016). Informe temático: Migración y Derechos Humanos, Santiago, [fecha de consulta: 29 de octubre de 2017]. [Disponible en: http://www.derecho.uchile.cl/centro-de-derechoshumanos/publicaciones/130489/informes-tematicos].

Centro de Derechos Humanos Universidad Diego Portales (2012). Análisis inicial a la propuesta del Gobierno para la nueva normativa de consulta a los pueblos indigenas, Santiago, [fecha de consulta: 29 de octubre de 2017]. [Disponible en http://www.derechoshumanos.udp.cl/derechoshumanos/ images/Publicaciones/Documentos/Sch\%C3\%B6nsteiner+-+An\%C3\%A1 lisis+inicial+a+la+propuesta+de+gobierno+para+la+nueva+normativa+de+c onsulta+a+los+pueblos+ind\%C3\%ADgenas.pdf].

$\mathrm{CIDH}$ (2007). Acceso a la justicia para las mujeres víctimas de violencia en las Américas. OEA/Ser.L/V/II, Doc. 68, [fecha de consulta: 29 de octubre de 
2017]. [Disponible en: https://www.cidh.oas.org/women/Acceso07/indiceacceso.htm].

DEM (2016). Migración en Chile 2005-2014. Departamento Extranjería y Migración Ministerio del Interior y Seguridad Pública, Santiago, [fecha de consulta: 29 de octubre de 2017]. [Disponible en: http://www.extranjeria.gob.cl/media/2016/02/Anuario-Estad\%C3\%ADstico-Nacional-Migraci\%C3\%B3nen-Chile-2005-2014.pdf].

DPP (2012). Comentarios a fallos relevantes en materia de defensa de imputados de pueblos originarios. Algunos aspectos para la mejor aplicación del modelo de defensa penal. Santiago, [fecha de consulta: 29 de octubre de 2017]. [Disponible en: http://www.biblio.dpp.cl/biblio/DataBank/6367.pdf].

DT (2011). ¿La maternidad castigada? Discriminación y malos tratos. Departamento de Estudios Dirección del Trabajo, Santiago, [fecha de consulta: 29 de octubre de 2017]. [Disponible en:http://www.dt.gob.cl/portal/1626/ articles-103042_archivo_01.pdf].

INDH (2013). El deber de consulta previa en la propuesta de Reglamento el Sistema de Evaluación Ambiental, Santiago, [fecha de consulta: 29 de octubre de 2017]. [Disponible en: http://bibliotecadigital.indh.cl/bitstream/handle/123456789/529/minuta?sequence=1].

SERNAM (2009). Análisis y evaluación de la ruta crítica en mujeres afectadas por violencia en la relación de pareja. Documento de Trabajo No 107, Santiago, [fecha de consulta: 29 de octubre de 2017]. [Disponible en: http://estudios. sernam.cl/?m=e\&i=79].

SCJN (2015). Protocolo para juzgar con perspectiva de género. Haciendo realidad el derecho a la igualdad. 2a edición. México D.F., [fecha de consulta: 29 de octubre de 2017]. [Disponible en: http://187.174.173.99:8080/leyes/ protocolos/3.pdf].

\section{JURISPRUDENCIA CITADA}

\section{Corte Interamericana de Derechos Humanos}

Corte IDH. El derecho a la información sobre la asistencia consular en el marco de las garantías del debido proceso legal. Opinión Consultiva OC-16/99 de 1 de octubre de 1999. Serie A No 16. 
Corte IDH. Condición jurídica y derechos de los migrantes indocumentados. Opinión Consultiva OC-18/03 de 17 de septiembre de 2003. Serie A No 18.

Corte IDH. Caso Montero Aranguren y otros (Retén de Catia) vs. Venezuela. Excepción Preliminar, Fondo, Reparaciones y Costas. Sentencia de 5 de julio de 2006. Serie C No 150.

Corte IDH. Caso Fernández Ortega y otros vs. México. Excepción Preliminar, Fondo, Reparaciones y Costas. Sentencia de 30 de agosto de 2010. Serie C No 215.

Corte IDH. Caso Rosendo Cantú y otra vs. México. Excepción Preliminar, Fondo, Reparaciones y Costas. Sentencia de 31 de agosto de 2010. Serie C No 216. Corte IDH. Caso Vera Vera y otra vs. Ecuador. Excepción Preliminar, Fondo, Reparaciones y Costas. Sentencia de 19 de mayo de 2011. Serie C No 226. Corte IDH. Caso Atala Riffo y niñas vs. Chile. Fondo, Reparaciones y Costas. Sentencia de 24 de febrero de 2012. Serie C No 239.

Corte IDH. Caso Pacheco Teruel y otros vs. Honduras. Fondo, Reparaciones y Costas. Sentencia de 27 de abril de 2012. Serie C No 241.

Corte IDH. Caso Pueblo Indigena Kichwa de Sarayaku vs. Ecuador. Fondo y reparaciones. Sentencia de 27 de junio de 2012. Serie C No 245.

Corte IDH. Caso Véliz Franco y otros vs. Guatemala. Excepciones Preliminares, Fondo, Reparaciones y Costas. Sentencia de 19 de mayo de 2014. Serie C No 277.

Corte IDH. Derechos y garantías de niñas y niños en el contexto de la migración y/o en necesidad de protección internacional. Opinión Consultiva OC-21/14 de 19 de agosto de 2014. Serie A No 21.

Corte IDH. Caso Gonzales Lluy y otros vs. Ecuador. Excepciones Preliminares, Fondo, Reparaciones y Costas. Sentencia de 1 de septiembre de 2015. Serie C No 298.

\section{Corte Suprema}

Corte Suprema, rol No 2840-2008, 25 de noviembre de 2008.

Corte Suprema, rol No 4078-2010, 14 de octubre de 2010.

Corte Suprema, rol No 258-2011, 13 de julio de 2011.

Corte Suprema, rol No 10090-2011, 22 de marzo de 2012.

Corte Suprema, rol No 11040-2011, 30 de marzo de 2012.

Corte Suprema, rol No 6041-2012, 26 de septiembre de 2012. 
Corte Suprema, rol No 9075-2012, 30 de enero de 2013.

Corte Suprema, rol No 3010-2013, 26 de septiembre de 2013.

Corte Suprema, rol No 1515-2014, 22 de abril de 2014.

Corte Suprema, rol No 2892-2014, 29 de abril de 2014.

Corte Suprema, rol No 11521-2014, 12 de junio de 2014.

Corte Suprema, rol No 10916-2014, 30 de junio de 2014.

Corte Suprema, rol No 11299-2014, 7 de octubre de 2014.

Corte Suprema, rol No 22455-2014, 30 de octubre de 2014.

Corte Suprema, rol No 8891-2014, 15 de enero de 2015.

Corte Suprema, rol No 1059-2015, 20 de enero de 2015.

Corte Suprema, rol No 1274-2015, 27 de enero de 2015.

Corte Suprema, rol No 2309-2015, 19 de febrero de 2015.

Corte Suprema, rol No 12492-2014, 18 de marzo de 2015.

Corte Suprema, rol No 3694-2015, 23 de marzo de 2015.

Corte Suprema, rol No 12356-2015, 2 de septiembre de 2015.

Corte Suprema, rol No 28842-2015, 20 de enero de 2016.

Corte Suprema, rol No 17976-2016, 11 de abril de 2016.

Corte Suprema, rol No 38337-2016, 17 de julio de 2016.

Corte Suprema, rol No 32081-2014, 30 de agosto de 2016.

Corte Suprema, rol No 35244-2016, 5 de septiembre de 2016.

Corte Suprema, rol No 44037-2016, 29 de noviembre de 2016.

Corte Suprema, rol No 92795-2016, 1 de diciembre de 2016.

Corte Suprema, rol No 65349-2016, 30 de enero de 2017.

Corte Suprema, rol No 3990-2017, 16 de febrero de 2017.

Corte Suprema, rol No 4764-2017, 9 de mayo de 2017.

Corte Suprema, rol No 223-2017, 9 de mayo de 2017.

Corte Suprema, rol No 30361-2017, 22 de junio de 2017.

Corte Suprema, rol No 35237-2016, 30 de agosto de 2017.

Corte Suprema, rol No 4935-2017, 14 de septiembre de 2017.

\section{Cortes de Apelaciones}

Corte de Apelaciones de Antofagasta, rol No 68-2013, 7 de diciembre de 2013. Corte de Apelaciones de Antofagasta, rol No 37-2014, 28 de julio de 2014. 
Corte de Apelaciones de Antofagasta, rol No 87-2017, 25 de abril de 2017. Corte de Apelaciones de Antofagasta, rol No 149-2017, 2 de junio de 2017. Corte de Apelaciones de Antofagasta, rol No 231-2017, 10 de agosto de 2017. Corte de Apelaciones de Arica, rol No 9-2011, 4 de marzo de 2011. Corte de Apelaciones de Arica, rol No 359-2011, 2 de noviembre de 2011. Corte de Apelaciones de Arica, rol No 182-2013, 25 de noviembre de 2013. Corte de Apelaciones de Arica, rol No 48-2017, 24 de febrero de 2017. Corte de Apelaciones de Arica, rol No 196-2017, 4 de julio de 2017. Corte de Apelaciones de Chillán, rol No 339-2016, 5 de abril de 2016. Corte de Apelaciones de Copiapó, rol No 290-2015, 20 de octubre de 2015. Corte de Apelaciones de Copiapó, rol No 328-2015, 17 de noviembre de 2015. Corte de Apelaciones de Copiapó, rol No 341-2015, 1 de diciembre de 2015. Corte de Apelaciones de Copiapó, rol No 202-2016, 10 de agosto de 2016. Corte de Apelaciones de Copiapó, rol No 263-2016, 13 de octubre de 2016. Corte de Apelaciones de Copiapó, rol No 186-2017, 13 de junio de 2017. Corte de Apelaciones de Iquique, rol No 113-2014, 14 de noviembre de 2014. Corte de Apelaciones de Iquique, rol No 56-2015, 31 de marzo de 2015. Corte de Apelaciones de Iquique, rol No 66-2015, 27 de abril de 2015. Corte de Apelaciones de Iquique, rol No 105-2016, 30 de agosto de 2016. Corte de Apelaciones de Iquique, rol No 859-2016, 9 de diciembre de 2016. Corte de Apelaciones de La Serena, rol No 516-2016, 10 de enero de 2017. Corte de Apelaciones de San Miguel, rol No 260-2012, 7 de agosto de 2012. Corte de Apelaciones de San Miguel, rol No 869-2014, 23 de junio de 2014. Corte de Apelaciones de San Miguel, rol No 19354-2010, 9 de abril de 2015. Corte de Apelaciones de San Miguel, rol No 1769-2016, 5 de septiembre de 2016. Corte de Apelaciones de San Miguel, rol No 47926-2016, 13 de diciembre de 2016.

Corte de Apelaciones de Santiago, rol No 1458-2007, 9 de noviembre de 2007. Corte de Apelaciones de Santiago, rol No 1794-2010, 31 de enero de 2011. Corte de Apelaciones de Santiago, rol No 3766-2011, 8 de julio de 2011. Corte de Apelaciones de Santiago, rol No 1682-2011, 10 de enero de 2012. Corte de Apelaciones de Santiago, rol No 19-2013, 21 de enero de 2013. Corte de Apelaciones de Santiago, rol No 1244-2013, 23 de julio de 2013. Corte de Apelaciones de Santiago, rol No 50535-2015, 20 de julio de 2015. 
Corte de Apelaciones de Santiago, rol No 53381-2015, 7 de agosto de 2015. Corte de Apelaciones de Santiago, rol No 51704-2015, 20 de agosto de 2015. Corte de Apelaciones de Santiago, rol No 2083-2015, 4 de diciembre de 2015. Corte de Apelaciones de Santiago, rol No 13932-2017, 4 de mayo de 2017. Corte de Apelaciones de Puerto Montt, rol No 36-2010, 27 de julio de 2010. Corte de Apelaciones de Puerto Montt, rol No 239-2011, 11 de octubre de 2011. Corte de Apelaciones de Punta Arenas, rol No 116-2011, 20 de enero de 2012. Corte de Apelaciones de Punta Arenas, rol No 28-2012, 4 de mayo de 2012. Corte de Apelaciones de Punta Arenas, rol No 2-2016, 12 de febrero de 2016. Corte de Apelaciones de Punta Arenas, rol No 8-2017, 28 de junio de 2017. Corte de Apelaciones de Temuco, rol No 99-2009, 25 de febrero de 2009. Corte de Apelaciones de Temuco, rol No 711-2011, 17 de agosto de 2011. Corte de Apelaciones de Temuco, rol No 955-2011, 27 de octubre de 2011. Corte de Apelaciones de Temuco, rol No 1136-2011, 21 de diciembre de 2011. Corte de Apelaciones de Temuco, rol No 499-2012, 17 de julio de 2012. Corte de Apelaciones de Temuco, rol No 581-2012, 2 de agosto de 2012. Corte de Apelaciones de Temuco, rol No 1920-2012, 15 de diciembre de 2012. Corte de Apelaciones de Temuco, rol No 220-2013, 3 de mayo de 2013. Corte de Apelaciones de Temuco, rol No 3385-2014, 21 de noviembre de 2014. Corte de Apelaciones de Temuco, rol No 497-2015, 15 de mayo de 2015. Corte de Apelaciones de Temuco, rol No 445-2015, 19 de agosto de 2015. Corte de Apelaciones de Temuco, rol No 4512-2015, 11 de noviembre de 2015. Corte de Apelaciones de Temuco, rol No 1171-2015, 12 de noviembre de 2015. Corte de Apelaciones de Temuco, rol No 682-2016, 26 de mayo de 2016. Corte de Apelaciones de Temuco, rol No 1156-2016, 15 de noviembre de 2016. Corte de Apelaciones de Temuco, rol No 6143-2016, 13 de diciembre de 2016. Corte de Apelaciones de Valdivia, rol No 501-2011, 4 de mayo de 2012. Corte de Apelaciones de Valdivia, rol No 8-2013, 13 de marzo de 2013. Corte de Apelaciones de Valdivia, rol No 2149-2014, 3 de enero de 2014. Corte de Apelaciones de Valdivia, rol No 69-2016, 25 de junio de 2016. Corte de Apelaciones de Valdivia, rol No 140-2017, 8 de agosto de 2017. 